
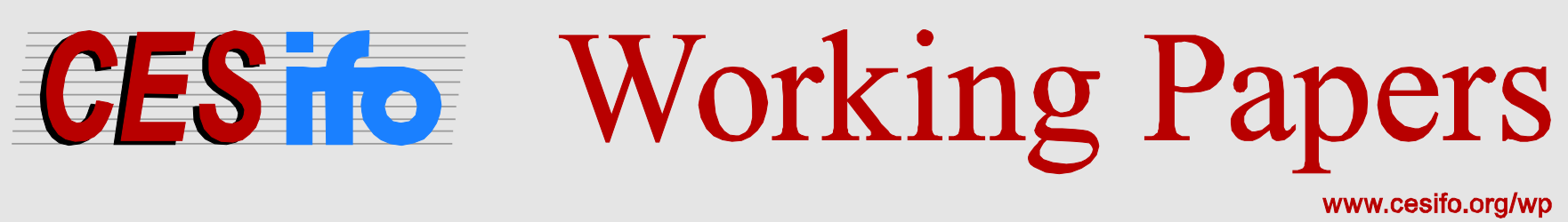

\title{
Conservatism Correction for the Market-To-Book Ratio and Tobin's $q$
}

\author{
Maureen McNichols \\ Madhav V. Rajan \\ Stefan Reichelstein
}

CESIFO WORKING PAPER NO. 4626

CATEGORY 11: INDUSTRIAL ORGANISATION

FEBRUARY 2014

An electronic version of the paper may be downloaded

- from the SSRN website:

- from the RePEc website:

- from the CESifo website:

WWW.SSRN.com

www.RePEc.org

www.CESifo-group.org/wp

\section{CESifo}




\title{
Conservatism Correction for the Market-To-Book Ratio and Tobin's $q$
}

\begin{abstract}
We decompose the market-to-book ratio into two additive components: a conservatism correction factor and a future-to-book ratio. The conservatism correction factor exceeds the benchmark value of one whenever the accounting for past transactions has been subject to an (unconditional) conservatism bias. The observed history of a firm's past investments allows us to calculate the magnitude of its conservatism correction factor, resulting in an average value that is about two-thirds of the overall market-to-book ratio. We demonstrate that our measure of Tobin's $q$, obtained as the market-to-book ratio divided by the conservatism correction factor, has greater explanatory power in predicting future investments than the market-to-book ratio by itself. Our model analysis derives a number of structural properties of the conservatism correction factor, including its sensitivity to growth in past investments, the percentage of investments in intangibles, and the firm's cost of capital. We provide empirical support for these hypothesized structural properties.
\end{abstract}

JEL-Code: M410, L250, G110.

Maureen McNichols
Graduate School of Business
Stanford University
Stanford CA / USA
fmcnich@stanford.edu

Stefan Reichelstein

Graduate School of Business

Stanford University

Stanford CA / USA

reichelstein@stanford.edu
Madhav V. Rajan

Graduate School of Business

Stanford University

Stanford CA / USA

mrajan@stanford.edu

December 18, 2013

We thank William Beaver, James Ohlson, Alexander Nezlobin, Stephen Penman (editor), Stephen Ryan, two anonymous reviewers, and workshop participants at Berkeley, Copenhagen (Interdisciplinary Workshop), Harvard, ISB (Hyderabad), Michigan, Muenchen (LMU), Northwestern, NYU, WHU, and Stanford for their valuable comments. We also acknowledge the excellent research assistance of Maria Correia, Moritz Hiemann, Eric So, Yanruo Wang, and Anastasia Zakolyukina. 


\section{Introduction}

The market-to-book ratio is commonly defined as the market value of a firm's equity divided by the book value of equity. It is well understood that this ratio exhibits considerable variation not only over time but also at any given point in time, across industries and even across firms within the same industry. For instance, Penman (2009, p. 43) illustrates these variations by plots showing the market-to-book ratio of U.S. firms in different industries over time. We seek to obtain theoretical and empirical insights into the market-to-book ratio ratio by identifying a component of this ratio that is attributable to unconditional accounting conservatism. ${ }^{1}$ This component, which we refer to as the conservatism correction factor, is given by the replacement value of a firm's assets relative to the book value of assets as recorded under the applicable financial reporting rules.

The conceptual significance of the conservatism correction factor is that one obtains a measure of Tobin's $q$ when the market-to-book ratio is divided by the conservatism correction factor. In our model, a Tobin's $q$ in excess of one indicates that the firm is expected to make positive economic profits in the future. ${ }^{2}$ Conservative accounting reflects that the depreciation of operating assets is accelerated relative to the benchmark of replacement cost accounting. This may be due to the lack of capitalizing some investment expenditures, such as those corresponding to R\&D or advertising. Conservative accounting also arises if straight-line depreciation, commonly applied for operating assets, is accelerated relative to the underlying useful life of an asset and its anticipated productivity pattern.

Our measure of the conservatism correction factor can be calculated for a specific firm in a particular year based on the history of past investments, the percentage of intangible investments, and the (estimated) useful life of its operating assets. As a first validation, we verify that the resulting conservatism correction is not excessive insofar as the implied measure of Tobin's $q$ does indeed exceed one, at least on average. We revisit earlier studies that have examined the ability of Tobin's $q$ to predict a firm's future investment. Since in these studies the empirical proxy for Tobin's $q$ is the market-to-book ratio, a natural question is whether our decomposition of the market-to-book ratio ratio can improve these

\footnotetext{
${ }^{1}$ Without attempting to summarize the extensive literature on accounting conservatism, we note that parts of the theoretical literature on unconditional conservatism take a market-to-book ratio greater than one as a manifestation of conservative accounting; see, for example, Feltham and Ohlson (1995, 1996), Zhang (2000), and Ohlson and Gao (2006).

${ }^{2}$ This calibration is consistent with Ross, Westerfield and Jaffe (2005, p. 41) who state: "Firms with high $q$ ratios tend to be those firms with attractive investment opportunities, or a significant competitive advantage." See also Lindenberg and Ross (1986), Landsman and Shapiro (1995) and Roll and Weston (2008).
} 
predictions. To that end, we hypothesize and establish that, after controlling for the marketto-book ratio, there is a significant negative association between the conservatism correction factor and next period's investment. Furthermore, we run a direct "horse-race" between the market-to-book ratio and our measure of Tobin's $q$ to establish that the latter variable has indeed better explanatory power for future investments.

The analytical part of our paper characterizes the magnitude and structural properties of the conservatism correction factor in terms of its constituent variables, including the degree of accounting conservatism, past growth in investments, and the cost of capital. ${ }^{3}$ Specifically, the model predicts that the conservatism correction factor is decreasing in higher rates of past investment growth and furthermore that this negative association is more pronounced for firms that exhibit a higher percentage of intangibles investments and therefore are more prone to conservative accounting biases. ${ }^{4}$ Finally, we establish analytically that the conservatism correction factor is increasing in the cost of capital, reflecting that ceteris paribus incumbent assets recorded at their effective replacement value become more valuable.

For further empirical validation of our conservatism measure, we exploit that the marketto-book ratio can be additively decomposed into the conservatism correction factor and a second component, which we refer to as the future-to-book ratio. Its numerator represents investors' expectations regarding the firm's future discounted economic profits. The futureto-book ratio is determined by both past and future investments, with the latter expected to be made optimally in light of anticipated future revenue opportunities. This ratio thus incorporates the anticipated "growth opportunities" frequently mentioned in connection with high market-to-book ratios. Negative future-to-book values can (and do) arise because future value is partly driven by past investments that are "locked-in" irreversibly at the present date. The expected future economic profits associated with these investments may be negative if future revenue prospects are assessed less favorably at the present time compared to the time at which the investments were undertaken. For firms operating in a competitive environment, investors expect zero economic profits, and therefore the market-to-book ratio reduces to the conservatism correction.

We form an estimate of the future-to-book ratio by capitalizing the firm's current economic profits. ${ }^{5}$ By subtracting the estimated future-to-book ratio factor from the observed

\footnotetext{
${ }^{3}$ Our model framework builds on the notion that firms undertake a sequence of overlapping investments in productive capacity. That feature is also central to the models in Arrow (1964), Rogerson (2008), Rajan and Reichelstein (2009), and Nezlobin (2012).

${ }^{4}$ For the market-to-book ratio, the predicted impact is ambiguous since both the numerator and the denominator of this ratio are increasing in higher past growth.

${ }^{5}$ This approach is broadly consistent with the valuation model formulated in Nezlobin (2012), where the capitalization of current economic profits reflects both the discount rate and the rate of growth in the firm's
} 
market-to-book ratio, we then obtain an estimate for the conservatism correction factor. This estimate does align reasonably well in magnitude with the inferred conservatism correction factor. Importantly, this estimate does serve as the dependent variable in our tests providing empirical support for the theoretical predictions derived from the model. Taken together, our findings speak to the interaction of accounting conservatism, past growth and anticipated future growth opportunities in shaping the market-to-book ratio.

In relating our work to the literature, we first note that our measure of the conservatism correction factor is conceptually related to the C-score of Penman and Zhang (2002). The calculation of their score is motivated by "biased applications of historical cost accounting" (page 204) and thus includes R\&D and advertising expenditures, though it does not include possible biases in the choice of depreciation schedule for capitalized assets. While our analysis examines the portion of the market-to-book ratio that is related to conservatism, so as to obtain an improved measure of Tobin's $q$, Penman and Zhang (2002) seek to relate their C-score to the quality of earnings and stock returns.

Among earlier studies that have examined the impact of accounting conservatism on the the market-to-book ratio, we mention, in particular, Beaver and Ryan (2005) and Roychowdhury and Watts (2007). A common feature of their studies is a decomposition of equity market values into multiple components, only some of which are reflected in current book values. Consistent with our framework, the direct expensing of intangible investments and biases in the depreciation rules are a major source of conservatism. Both of these papers also link unconditional conservatism to measures of conditional conservatism such as the timeliness of earnings. ${ }^{6}$ The distinctive feature of our additive decomposition of the marketto-book ratio into a conservatism correction factor and future-to-book ratio is that it allows us to quantify a component of the market-to-book ratio that is attributable to unconditional conservatism and to examine analytically and empirically the structural properties of this component.

A recurring theme in the earlier empirical literature on the market-to-book in accounting and finance has been the ability of this ratio to predict future stock returns and future accounting rates of return. For instance, Penman (1996) examines how the market-to-book ratio and the price-to-earnings ratio jointly relate to a firm's future return on equity. Beaver and Ryan (2000) hypothesize that the market-to-book ratio is affected by two accounting related components which they term bias and lag, respectively. Both of these factors are conjectured to be negatively related to future accounting rates of return and the authors find

sales revenues.

${ }^{6}$ We note that our present model formulation is not suited to address issues of conditional conservatism, as considered, for instance, in Basu (1997) and Watts (2003) 
empirical support for this prediction. In contrast to our decomposition approach, however, both the bias and the lag component in the market-to-book ratio are extracted by a regression of the market-to-book ratio on both current and past annual security returns with fixed firm effects.

The positive association between the market-to-book ratio and future security returns has been documented robustly in a range of earlier studies. However, there appears to be no consensus for this relation. While Fama and French $(1992,2006)$ point to risk as an explanation, other authors have invoked mispricing arguments for this association; see, for instance, Rosenberg, Reid and Lanstein (1985), and Lakonishok, Shleifer and Vishny (1994). In most of the earlier finance literature, it appears that book value is merely viewed as a convenient normalization factor in the calculation of the book-to-market ratios, without recognition that the measurement bias in this variable may differ considerably across firms. ${ }^{7}$ In contrast to the above mentioned studies, the objective of the present paper is not an improved understanding of the relation between the market-to-book ratio and future returns. Instead, we seek to identify the share of the overall premium expressed in the market-to-book ratio that is attributable to accounting conservatism and past growth in operating assets.

The remainder of this paper is organized as follows. Section 2 contains the model framework and derives a sequence of propositions. These lead to the formulation of a set of hypotheses for empirical testing in Section 3. Empirical proxies, our data set and the actual empirical results are reported in Section 4. We conclude in Section 5. Two separate appendices contain the tables and the proofs of the analytical propositions.

\section{Model Framework}

Our model examines an all-equity firm that undertakes a sequence of investments in productive capacity. The assets recorded for these investments are the firm's only operating assets. In particular, we abstract from working capital and debt. Furthermore, any free cash is assumed to be paid out immediately to shareholders. Accordingly, the denominator in the firm's market-to-book ratio is given by the book value of equity, which is equal to the book value of operating assets.

Capacity can be acquired at a constant unit cost. Without loss of generality, one unit of capacity requires a cash outlay of one dollar. New investments generate capacity with a lag

\footnotetext{
${ }^{7}$ The addition of accounting information is, of course, the general motivation for studies like those in Piotroski (2000) and Mohanram (2005). By including firm-specific scores derived from financial statement analysis, these authors are able to refine the association between market-to-book ratios and stock returns by partitioning firms with similar market-to-book ratios into different subgroups.
} 
of $L$ periods and have an overall useful life of $T$ periods. Specifically, an expenditure of $I_{t}$ dollars at date $t$ will add productive capacity to produce $x_{\tau} \cdot I_{t}$ units of output at date $t+\tau$, with $x_{1}=x_{2}=\ldots=x_{L-1}=0$ and $x_{t}>0$ for $L \leq t \leq T$. At date $T$, the total capacity currently available is thus determined by the investments $\left(I_{0}, \ldots, I_{T-L}\right)$. To allow for the possibility of decaying capacity, possibly to reflect the need for increased maintenance and repair over time, we specify that $1=x_{L} \geq x_{L+1} \geq \ldots \geq x_{T}>0$. For our empirical analysis, we will assume that the productivity of assets conforms to the one-hoss shay pattern, where $x_{t}=1$ for $t>L$. Alternatively, a pattern of geometric decline would set $x_{t}=x^{t-L}$ for some $x \leq 1 .^{8}$

For a given history of investments, $\mathbf{I}_{T} \equiv\left(I_{0}, \ldots, I_{T}\right)$, the overall productive capacity at date $T$ becomes:

$$
K_{T}\left(\mathbf{I}_{T}\right)=x_{T} \cdot I_{0}+x_{T-1} \cdot I_{1}+\ldots+x_{L+1} \cdot I_{T-L-1}+x_{L} \cdot I_{T-L}
$$

The first term in the above expression reflects the final period of productive capacity for the earliest investment made by the firm $\left(I_{0}\right)$. The last term represents the first period of productive use $\left(x_{L}=1\right)$ for the investment made at time $T-L$.

\subsection{Book- and market values}

The accounting for capacity investments is the only source of accruals in our model. In particular, all variable costs are incurred on a cash basis and can therefore, without loss of generality, be included in net sales revenue. Investments comprise expenditures for tangible and intangible assets, e.g., expenditures for plant, property, and equipment, as well as expenditures for process control, training, and development. Our analysis takes the ratio of tangible to intangible assets as exogenous. Consistent with the external financial reporting rules employed in most countries, we assume that intangible investments are fully expensed at the time the investment expenditure is incurred. Accordingly the initial book value per dollar of investment, $b v_{0}$, is given by:

$$
b v_{0}=(1-\alpha)
$$

where the parameter $\alpha \geq 0$ indicates the proportion of investment expenditures that are directly expensed. The entire depreciation schedule for capitalized investments will be denoted by $\mathbf{d}=\left(\alpha, d_{1}, d_{2}, \ldots d_{T}\right)$, with $\sum_{t=1}^{T} d_{t}=1$. The depreciation charge in period $t$ of the asset's existence is given by:

$$
d e p_{t}=b v_{0} \cdot d_{t}
$$

\footnotetext{
${ }^{8}$ In connection with solar power panels, it is commonly assumed that electricity yield is subject to "systems degradation," which is modeled as a pattern of geometrically declining capacity levels (Campbell, 2008).
} 
for $1 \leq t \leq T$. Since $b v_{t}=b v_{t-1}-d e p_{t}$, an asset acquired at date 0 will have a remaining book value of:

$$
b v_{t}=b v_{0} \cdot\left(1-\sum_{i=1}^{t} d_{i}\right)
$$

at date $t$. For future reference, we also introduce the "residual income" charges $z_{t}(\mathbf{d})=$ $d e p_{t}+r \cdot b v_{t-1}$, where $r$ denotes the applicable cost of capital. Setting $\gamma \equiv \frac{1}{1+r}$ and $z_{0}(\mathbf{d})=\alpha$, the conservation property of residual income then implies that

$$
\sum_{t=0}^{T} z_{t}(\mathbf{d}) \cdot \gamma^{t}=1 .
$$

Given an investment history, $\mathbf{I}_{T}=\left(I_{0}, \ldots, I_{T}\right)$, the aggregate book value at date $T$ is then given by:

$$
B V_{T}\left(\mathbf{I}_{T}, \mathbf{d}\right)=b v_{T-1} \cdot I_{1}+b v_{T-2} \cdot I_{2}+\ldots+b v_{0} \cdot I_{T}
$$

Among the $T$ terms in the above representation, the first $T-L$ terms refer to investments that were in use during period $T$, in chronological order of their inception. The latter $L$ terms denote the more recent investments which, because of the $L$-period lag, have not yet come into productive use.

The denominator in the market-to-book ratio represents the book value obtained under the applicable external financial reporting rules. We denote these asset valuation rules by $\mathbf{d}^{o}$ and the corresponding book value by $B V_{T}\left(\mathbf{I}_{T}, \mathbf{d}^{o}\right)$. In the empirical part of our analysis, we operationalize $\mathbf{d}^{o}$ by the financial reporting practices in the United States. Accordingly, our empirical analysis will assume throughout that investments in intangibles are directly expensed and investments in plant, property, and equipment are depreciated according to the straight-line rule.

Investors are assumed to expect future investment decisions to be made so as to maximize firm value. In particular, there are no frictions due to agency problems. For reasons of parsimony, we also present the valuation problem as one of certainty, that is, investors have complete foresight of the firm's future growth opportunities. As a consequence, they anticipate the stream of future free cash flows that the firm derives from past investments in productive capacity and optimally chosen future investments. ${ }^{9}$ Let $R_{T+t}\left(K_{T+t}\right)$ denote the net revenue (operating cash flow) that the firm can obtain at date $T+t$ if it has capacity

\footnotetext{
${ }^{9}$ Conceptually, it would not be difficult to extend our model formulation so as to include uncertainty and investors' expectations. Such an extension would, however, not serve any particular purpose for either our theoretical or our empirical analysis.
} 
level $K_{T+t}$ in place. The future capacity levels are a function of the investment history $\mathbf{I}_{T}$ and the future investment levels $\mathbf{I}_{\infty} \equiv\left(I_{T+1}, I_{T+2}, \ldots\right)$. We denote the entire sequence of investments by $\mathbf{I} \equiv\left(\mathbf{I}_{T}, \mathbf{I}_{\infty}\right)$. The firm's market value can then be expressed as:

$$
M V_{T}\left(\mathbf{I}_{T}\right)=\max _{\left\{\mathbf{I}_{\infty}\right\}}\left\{\sum_{t=1}^{\infty}\left[R_{T+t}\left(K_{T+t}\left(\mathbf{I}_{T}, \mathbf{I}_{\infty}\right)\right)-I_{T+t}\right] \cdot \gamma^{t}\right\},
$$

where $\gamma=\frac{1}{1+r}$ again denotes the discount factor corresponding to the cost of capital, $r$. Let $\hat{\mathbf{I}}_{\infty}\left(\mathbf{I}_{T}\right)$ denote a sequence of future investments that maximizes (4), conditional on $\mathbf{I}_{T}$. For notational compactness, we also define $\hat{\mathbf{I}} \equiv\left(\mathbf{I}_{T}, \hat{\mathbf{I}}_{\infty}\left(\mathbf{I}_{T}\right)\right)$. Our principal object of study is the market-to-book ratio:

$$
M B_{T}=\frac{M V_{T}\left(\mathbf{I}_{T}\right)}{B V_{T}\left(\mathbf{I}_{T}, \mathbf{d}^{o}\right)}
$$

\subsection{Conservatism correction}

We seek to apply a correction factor to the denominator in the M-to-B ratio so as to undo any (unconditional) conservatism bias inherent in the financial accounting rules embodied in $\mathbf{d}^{o}$. The correction we identify generates the mapping from the market-to-book ratio to Tobin's $q$. Since $q$ is defined as enterprise market value divided by the replacement cost value of the firm's assets, the conservatism correction factor for an all-equity firm must be the replacement cost of the firm's assets relative to the reported book value of the assets. To operationalize the concept of replacement cost accounting, suppose hypothetically that the firm had access to a rental market for capacity services in which suppliers provide short-term (periodic) capacity services. If such a market were competitive, suppliers would charge a rental price at which they make zero economic profits on their investments. This competitive market price would be given by:

$$
c=\frac{\gamma^{-L}}{\sum_{t=L}^{T} x_{t} \cdot \gamma^{t-L}}=\frac{1}{\sum_{t=1}^{T} x_{t} \cdot \gamma^{t}},
$$

since the joint cost of acquiring one unit of capacity has been normalized to one. In the one-hoss shay scenario $\left(x_{t}=1\right)$, we therefore conclude that the normalized cost of one unit of capacity, available for one period or time, is given by the reciprocal of the value of an annuity of $\$ 1$ paid over $T$ years. Given an investment history, $\mathbf{I}_{T}$, the replacement value of the firm's assets is given by:

$$
B V_{T}^{*}\left(\mathbf{I}_{T}\right)=b v_{T-1}^{*} \cdot I_{1}+b v_{T-2}^{*} \cdot I_{2}+\ldots+b v_{0}^{*} \cdot I_{T}
$$


where $b v_{t}^{*}=c \cdot \sum_{i=t+1}^{T} x_{i} \cdot \gamma^{i-t}$. To interpret the expression in (7), we note that in a competitive rental market the replacement value of an asset acquired at date 0 will be $b v_{t}^{*}=c \cdot \sum_{i=t+1}^{T} x_{i} \cdot \gamma^{i-t}$ at date $t$, precisely because the used asset can generate rental revenues of $x_{i} \cdot c$ in the future periods $\{t+1, \ldots T\} .{ }^{10}$

The depreciation rule $\mathbf{d}^{*}$ that implements the book values $\left\{b v_{t}^{*}\right\}_{t=1}^{T}$ will be referred to as replacement cost accounting. ${ }^{11}$ It is readily verified that this rule requires assets to be fully capitalized, that is, $\alpha^{*}=0$. If furthermore $x_{t}=1$, the replacement cost depreciation schedule $\mathbf{d}^{*}$ is simply the annuity depreciation method. These depreciation charges are applied to the compounded book value $b v_{L-1}=b v_{0} \cdot(1+r)^{L-1} .{ }^{12}$ On the other hand, it can be shown that the $\mathbf{d}^{*}$ rule coincides with straight-line depreciation if practical capacity declines linearly over time.

Given the replacement cost depreciation schedule, $\mathbf{d}^{*}$, Tobin's $q$ can be expressed as:

$$
q \equiv \frac{M B_{T}}{C C_{T}}
$$

where

$$
C C_{T} \equiv \frac{B V_{T}\left(\mathbf{I}_{T}, \mathbf{d}^{*}\right)}{B V_{T}\left(\mathbf{I}_{T}, \mathbf{d}^{o}\right)}=\frac{b v_{T-1}^{*} \cdot I_{1}+b v_{T-2}^{*} \cdot I_{2}+\ldots+b v_{0}^{*} \cdot I_{T}}{b v_{T-1}^{o} \cdot I_{1}+b v_{T-2}^{o} \cdot I_{2}+\ldots+b v_{0}^{o} \cdot I_{T}}
$$

A common interpretation of Tobin' $q$ is that it captures future growth opportunities and future profitability. More specifically, Lindenberg and Ross (1981, p. 3) state: “...for firms engaged in positive investment, in equilibrium we expect $q$ to exceed one by the capitalized value of the Ricardian and monopoly rents which the firm enjoys." To formalize this statement in the context of our model, we invoke the residual income formula, which expresses market

\footnotetext{
${ }^{10}$ Without reference to a hypothetical rental market, Arrow (1964) and Rogerson (2008) derive the same unit cost of capacity in an infinite horizon setting with new investments in each period.

${ }^{11}$ Our notion of replacement cost accounting differs from the concept of unbiased accounting in Feltham and Ohlson (1995, 1996), Zhang (2000), and Ohlson and Gao (2006). Their notion of unbiased accounting is that the market-to-book ratio approaches a value of 1 asymptotically. In the literature on ROI, the concept of unbiased accounting is operationalized by the criterion that for an individual project the accounting rate of return should be equal to the project's internal rate of return; see, for instance, Beaver and Dukes (1974), Rajan, Reichelstein and Soliman (2007), and Staehle and Lampenius (2010). To satisfy this criterion, the accruals must generally reflect the intrinsic profitability of the project. In the special case where all projects have zero NPV, this criterion does coincide with our notion of unbiased accounting.

${ }^{12}$ When assets are not in productive use during the first $L$ periods, they become more valuable over time. Therefore the depreciation charges in the first $L-1$ periods are negative with $d_{t}^{*}=-r \cdot(1+r)^{t-1}$ for $1 \leq t \leq L-1$. This is exactly the accounting treatment that Ehrbar (1998) recommends for so-called "strategic investments," which are characterized by a long time lag between investments and subsequent cash inflows.
} 
value as book value plus future discounted residual incomes (Edwards and Bell 1961; Feltham and Ohlson 1996). Since this identity holds irrespective of the accounting rules, we can invoke it for the replacement cost accounting rule, $\mathbf{d}^{*}$, to obtain:

$$
M V_{T}\left(\mathbf{I}_{T}\right)=B V_{T}\left(\mathbf{I}_{T}, \mathbf{d}^{*}\right)+\sum_{t=1}^{\infty}\left[R_{T+t}\left(K_{T+t}(\hat{\mathbf{I}})\right)-H_{T+t}\left(\hat{\mathbf{I}}_{T+t}, \mathbf{d}^{*}\right)\right] \cdot \gamma^{t} .
$$

Here, $H_{T+t}(\cdot)$ denotes the residual income charges in period $T+t$, that is, the sum of depreciation and imputed book value charges on all past investments, that are still active at date $T+t$ :

$$
H_{T+t}\left(\mathbf{I}_{T+t}, \mathbf{d}^{*}\right) \equiv z_{T}\left(\mathbf{d}^{*}\right) \cdot I_{t}+\ldots+z_{1}\left(\mathbf{d}^{*}\right) \cdot I_{T+t-1} .
$$

The first term in (10) captures the depreciation and interest charge for the oldest investment undertaken at date $t$, while the final expression corresponds to the most recent investment at date $T+t-1$. Rogerson $(2008,2011)$ shows that with the replacement cost accounting rule $\mathbf{d}^{*}$ in place, the residual income charges are equal to the economic cost of the capacity used in the current period:

$$
H_{T+t}\left(\mathbf{I}_{T+t}, \mathbf{d}^{*}\right)=c \cdot K_{T+t}\left(\mathbf{I}_{T+t}\right)
$$

for any investment sequence $\mathbf{I}_{T+t}$. Thus the firm's market value can be expressed as the replacement cost of its existing assets, i.e., $B V_{T}\left(\mathbf{I}_{T}, \mathbf{d}^{*}\right)$ plus its future value:

$$
F V_{T}\left(\mathbf{I}_{T}\right) \equiv \sum_{t=1}^{\infty}\left[R_{T+t}\left(K_{T+t}(\hat{\mathbf{I}})\right)-c \cdot K_{T+t}(\hat{\mathbf{I}})\right] \cdot \gamma^{t}
$$

Future value measures the stream of discounted future economic profits, since a firm operating under conditions of zero economic profits (zero NPV on its investment projects), will have $R_{T+t}(K)=c \cdot K$ for all $K$. We conclude that, consistent with the verbal intuition of Lindenberg and Ross cited above,

$$
q=1+\frac{F V_{T}}{B V_{T}\left(\mathbf{I}_{T}, \mathbf{d}^{*}\right)},
$$

provided "economic profits" are equated with "Ricardian and monopoly rents."

Our analysis derived $C C_{T}$ as a means of obtaining Tobin's $q$ from the market-to-book ratio. At the same time, $C C_{T}$ provides an additive decomposition of the market-to-book ratio into conservatism correction and the future-to-book ratio, $F B_{T}$ :

$$
M B_{T}=C C_{T}+F B_{T}
$$


where

$$
F B_{T}=\frac{F V_{T}\left(\mathbf{I}_{T}\right)}{B V_{T}\left(\mathbf{I}_{T}, \mathbf{d}^{o}\right)} .
$$

Note that the second term in (12) can genuinely be interpreted as future value in the sense that $F V_{T}$ in (13) will be zero whenever the firm operates under conditions of zero economic profitability. The decomposition in (12) indicates that a market-to-book ratio greater than one may reflect either a conservatism correction factor exceeding one, a positive future value, or both. The factor $C C_{T}$ will exceed one, provided the asset valuation rule $\mathbf{d}^{o}$ is more accelerated than the replacement cost accounting in the sense that $b v_{t}^{o} \leq b v_{t}^{*}$ for all $t$. In that case, $C C_{T} \geq 1$ as all component ratios $\frac{b v_{t}^{*}}{b v_{t}^{o}}$ in (8) are greater than or equal to 1 . $^{13}$ While $C C_{T}$ is a function of the accounting rules and past investment decisions, future value reflects both past investment decisions and anticipated future investments. In particular, $F V_{T}$ need not be positive because anticipated future revenues at date $T$ could be lower than they were at the time the investments were undertaken. A longer lag, $L$, between the time investment expenditures are made and the time the investments become productive tends to increase the "likelihood" for a negative $F V_{T}$. Specifically, the first $L$ terms in $F V_{T}$, that is,

$$
\sum_{t=1}^{L}\left[R_{T+t}\left(K_{T+t}(\hat{\mathbf{I}})\right)-c \cdot K_{T+t}(\hat{\mathbf{I}})\right] \cdot \gamma^{t}=\sum_{t=1}^{L}\left[R_{T+t}\left(K_{T+t}\left(\mathbf{I}_{T}\right)\right)-c \cdot K_{T+t}\left(\mathbf{I}_{T}\right)\right] \cdot \gamma^{t}
$$

are determined entirely by past investment decisions.

\subsection{Structural properties of the conservatism correction factor}

Since firms with high market-to-book ratio ratios are frequently viewed as "growth" stocks, we proceed to investigate the impact of past growth in investments on the magnitude and behavior of the conservatism correction factor $C C_{T}$. To that end, the growth rate in investments in period $t$ will be denoted by $\lambda_{t}$. This rate is defined implicitly by:

$$
\left(1+\lambda_{t}\right) \cdot I_{t-1}=I_{t}
$$

Any investment history $\mathbf{I}_{T}$ induces a sequence of corresponding growth rates $\boldsymbol{\lambda}_{T}=\left(\lambda_{1}, . ., \lambda_{T}\right)$. Conversely, any initial investment $I_{0}$ combined with growth rates $\left(\lambda_{1}, . ., \lambda_{T}\right)$ defines an investment history $\mathbf{I}_{T}$. The aggregate book value $B V_{T}\left(\mathbf{I}_{T}, \mathbf{d}\right)$ at date $T$ can therefore be expressed as:

$$
B V_{T}\left(\boldsymbol{\lambda}_{T}, \mathbf{d}^{o} \mid I_{0}\right)=I_{0} \cdot\left[b v_{T-1}^{o}\left(1+\lambda_{1}\right)+b v_{T-2}^{o}\left(1+\lambda_{1}\right)\left(1+\lambda_{2}\right)+\ldots+b v_{0}^{o} \cdot \prod_{i=1}^{T}\left(1+\lambda_{i}\right)\right] .
$$

\footnotetext{
${ }^{13}$ See also Proposition 2 in Staehle and Lampenius (2010).
} 
Intuitively, the impact of growth on $C C_{T}$ depends on how the constituent ratios $\frac{b v_{t}^{*}}{b v_{t}^{o}}$ change over time. To state a general result, we introduce the following notion of uniformly accelerated depreciation.

Definition: The depreciation schedule $\mathbf{d}^{\circ}$ is uniformly more accelerated than the replacement cost accounting rule, $\mathbf{d}^{*}$, if:

$z_{t}\left(\mathbf{d}^{o}\right) \geq 0$, for $0 \leq t \leq L-1$, and $\frac{z_{t}\left(\mathbf{d}^{o}\right)}{x_{t}}$ is monotonically decreasing in $t$ for $L \leq t \leq T$.

It can be shown that the criterion of uniformly more accelerated depreciation is indeed stronger than the conventional criterion that one depreciation schedule is more accelerated than another if the book values corresponding to the former schedule are at each point in time lower than the ones corresponding to the latter schedule (Rajan and Reichelstein 2009). For the replacement cost accounting rule, $\mathbf{d}^{*}$, the inequalities in the preceding definition are met as equalities since the residual income charges are equal to the economic cost of the capacity used up in period $t$, that is, $z_{t}\left(\mathbf{d}^{*}\right)=c \cdot x_{t}$. In our empirical tests, we will assume that, for financial reporting purposes, firms expense their investments in intangibles and that all capitalized operating assets are depreciated according to the straight line rule. ${ }^{14}$ The corresponding residual income charges $z_{t}\left(\mathbf{d}^{o}\right) 0$ then satisfy the criterion of being uniformly accelerated provided the productive decay of assets conforms to the one-hoss shay rule $\left(x_{t}=\right.$ 1). To see this, we note that $z_{t}\left(\mathbf{d}^{o}\right) \geq 0$ during the construction phase $(0 \leq t \leq L-1)$, while the $z_{t}\left(\mathbf{d}^{o}\right)>0$ decrease linearly when the asset is in use because depreciation charges are constant and interest charges decline linearly with time.

Proposition 1: If $\mathbf{d}^{o}$ is uniformly more accelerated than the replacement cost accounting rule, $\mathbf{d}^{*}$, the conservatism correction factor $C C_{T}\left(\boldsymbol{\lambda}_{T}, \mathbf{d}^{o}\right)$ is monotone decreasing in each $\lambda_{t}$.

With uniformly more accelerated accounting, higher levels of growth in past investments thus lower the conservatism correction factor, due to a smaller divergence between the stated accounting book values and the replacement cost values. In the empirical part of our study, differences in unconditional conservatism across firms emerge due to two factors: (i) discrepancies between straight-line depreciation and the depreciation schedule prescribed by replacement cost accounting and (ii) differences in the parameter $\alpha$. Since the book value in the denominator of $M B_{T}$ is decreasing linearly in $\alpha$, we note that the market-to-book ratio, $M B_{T}$ is increasing and convex in $\alpha$. In conjunction with Proposition 1 we obtain a

\footnotetext{
${ }^{14}$ The AICPA's (2007, p. 399) Accounting Trends 83 Techniques survey of 600 Fortune 1000 firms reports that 592 of the sample firms applied straight-line accounting in reporting the value of their operating assets.
} 
prediction regarding the interaction between conservatism and growth for the Conservatism Correction factor. To that end, we use the notation $\mathbf{d}_{\alpha=0}^{o} \equiv\left(0, d_{1}^{o}, \ldots, d_{T}^{o}\right)$ to represent the depreciation schedule $\mathbf{d}^{o}$, assuming full capitalization of the initial investment. ${ }^{15}$ It follows immediately that:

$$
C C_{T}\left(\boldsymbol{\lambda}_{T}, \mathbf{d}^{o}\right)=\frac{1}{1-\alpha} \cdot C C_{T}\left(\boldsymbol{\lambda}_{T}, \mathbf{d}_{\alpha=0}^{o}\right)
$$

and we obtain the following result.

\section{Corollary 1:}

$$
\frac{\partial^{2}}{\partial \lambda_{t} \partial \alpha} C C_{T}\left(\boldsymbol{\lambda}_{T}, \mathbf{d}^{o}\right)<0
$$

We next turn to the impact of a higher cost of capital, $r$, on the conservatism correction factor. Intuitively, one would expect that a higher cost of capital makes the stock of past investments, $B V_{T}\left(\mathbf{I}_{T}, \mathbf{d}^{*}\right)$, more valuable. This turns out to be true subject to a regularity condition on the pattern of productivity levels, $\left(x_{L}, \ldots, x_{T}\right) .{ }^{16}$

Proposition 2: Suppose that $\mathbf{d}^{o}$ is independent of $r$. Then $C C_{T}$ is increasing in $r$ provided that, for all $t \geq L$, the pattern of productivity declines satisfies

$$
\frac{x_{t}}{x_{t+1}} \leq \frac{x_{t+1}}{x_{t+2}}
$$

One implication of Proposition 2 is that the market-to-book ratio of firms operating in competitive environments (zero economic profits) will be increasing in the cost of capital, since for these firms $M B_{T}$ reduces to $C C_{T}$. At first glance, this prediction appears counterintuitive: the book value in the denominator of $M B_{T}$ is independent of $r$ provided firms use straight-line depreciation (or any other schedule that is independent of $r$ ) for the portion of their investments that were capitalized in the first place. At the same time, the expression for $M V_{T}$ in (4) is decreasing in $r$, because future free cash flows are discounted at a higher rate. Yet such a ceteris paribus comparison would be misleading since a higher cost of capital also results in a higher unit cost of capacity $c$, and therefore higher net revenues will be required in order for the firm to break-even in terms of economic profit.

In order to obtain sharper insights about the magnitude and behavior of $C C_{T}$, we now impose additional structure on the model: constant growth $\left(\lambda_{t}=\lambda\right)$ and the assumption that

\footnotetext{
${ }^{15}$ It is readily verified that, if $\mathbf{d}^{o}$ is uniformly more accelerated than $\mathbf{d}^{*}=\left(0, d_{1}^{*}, d_{2}^{*}, . ., d_{T}^{*}\right)$, then so is $\mathbf{d}_{\alpha=0}^{o}$.

${ }^{16}$ The condition on the $x_{t}$ 's in the statement of Proposition 3 is sufficient but not necessary. This condition is also not very restrictive. For instance, it is satisfied by any $\boldsymbol{x}$ vector that decreases over time in either a linear or geometric fashion. The one-hoss shay scenario, where all $x_{t}=1$, is one particular admissible case.
} 
for financial reporting purposes partial expensing (fraction $\alpha \geq 0$ ) is followed by straightline depreciation over the period of productive use. The conservatism correction factor then reduces to the following simple form:

$$
C C_{T}=\frac{B V_{T}^{o}\left(\mathbf{I}_{T}, \mathbf{d}^{*}\right)}{B V_{T}\left(\mathbf{I}_{T}, \mathbf{d}^{o}\right)}=c \cdot \frac{\sum_{t=L}^{T} x_{t} \cdot\left(\gamma^{t}-\mu^{t}\right)}{\sum_{t=1}^{T} z_{t}\left(\mathbf{d}^{o}\right) \cdot\left(\gamma^{t}-\mu^{t}\right)},
$$

where $\mu \equiv \frac{1}{1+\lambda}, z_{t}\left(\mathbf{d}^{o}\right)=r \cdot(1-\alpha)$ for $1 \leq t \leq L-1$, and

$$
z_{t}\left(\mathbf{d}^{o}\right)=(1-\alpha) \cdot\left[\frac{1}{T-L+1}+r \cdot \frac{T-t+1}{T-L+1}\right] \text { for } L \leq t \leq T .
$$

For the one-hoss shay scenario, where $x_{t}=1$ for all $L \leq t \leq T$, we note that the accounting rules in (16) entail three distinct sources of conservatism: (i) an $\alpha$ percentage of investments is never capitalized, (ii) asset values are not compounded during the construction phase in periods 1 through $L-1$ and (iii) assets are depreciated according to the straight-line rule rather than the annuity depreciation rule during their productive phase in periods $L$ through $T$. Even for $\alpha=0$, the resulting book values $b v_{t}^{o}\left(\equiv b v_{t}\left(\mathbf{d}^{o}\right)\right.$ are strictly below the unbiased book values $b v_{t}^{*}{ }^{17}$ The difference between $b v_{t}^{*}$ and $b v_{t}^{o}$ is increasing in the parameter $L$.

Figure 1 illustrates the magnitude of the resulting conservatism correction factor $C C_{T}$ for different levels of growth. (The graphs in Figure 1 are based on the following parameter specifications: $L=1, r=10 \%$ and $T=15$.)

Figure 1 suggests that the impact of growth on $C C_{T}$ is rather uneven in the sense that the most significant drop in $C C_{T}$ occurs for moderately negative growth rates between -0.5 and zero. Thereafter $C C_{T}$ quickly approaches its asymptotic value, which in all three examples is equal to $\frac{1}{1-\alpha}$. For extremely negative growth rates $C C_{T}$ appears to flatten out rather than increase asymptotically without bound. Our final result shows that these observations do indeed hold at some level of generality. In deriving this result, we impose the restriction that the productive capacity of assets declines linearly over time:

$$
x_{t}=1-\beta \cdot(t-L)
$$

\footnotetext{
${ }^{17}$ Informally, this inequality follows from the following two observations. (i) On the interval $[0, L-1]$, it is clearly true that $b v_{t}^{*}>b v_{t}^{o}$; (ii) on the interval $[L, T-1]$ it must also be true that $b v_{t}^{*}>b v_{t}^{o}$, because $b v_{T}^{*}=b v_{T}^{o}=0$ and $b v_{t}^{*}$ is decreasing and concave on $[L, T]$, while $b v_{t}^{o}$ is a linear function of time.
} 


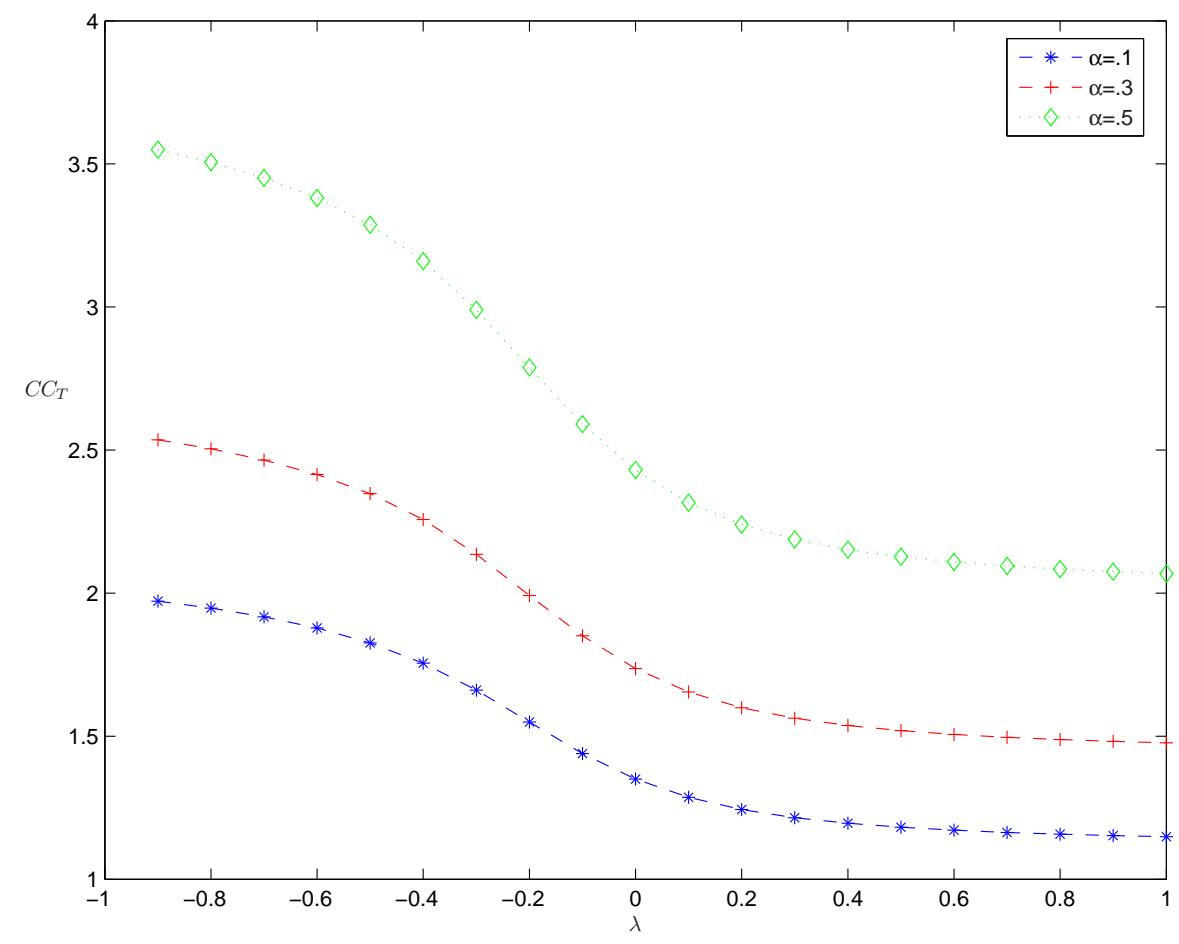

Figure 1: Conservatism Correction Factor

for $t \geq L$. Here, $\beta \geq 0$ captures the periodic decline in productive capacity once assets are in use. The one-hoss shay scenario corresponds to $\beta=0$. We assume that the rate of decline is not too great, in particular that $0 \leq \beta \leq \beta^{*} \equiv \frac{r}{1+r \cdot(T-L+1)}$. Under these assumptions, it can be verified that the combination of partial expensing and straight-line depreciation represents conservative accounting and, in fact, is uniformly more accelerated than replacement cost accounting. It will be notationally convenient to introduce the auxiliary function:

$$
h(s) \equiv \frac{s \cdot(1+s)^{T}}{(1+s)^{T}-1},
$$

for $s$ on the domain $[-1, \infty]$. The economic interpretation of $h(s)$ is that, if this amount is paid annually over $T$ years, the resulting present value is equal to 1 , provided future payments are discounted at the rate $s$. Therefore $h(\cdot)$ is increasing and convex over its domain, with $h(-1)=0, h(0)=1 / T$ and $h(\infty)=\infty$.

Proposition 3: Suppose $\mathbf{d}^{o}$ conforms to straight-line depreciation with partial expensing, $\lambda_{t}=\lambda$, and $x_{t}=1-\beta \cdot(t-L)$. Then, if $L=1$,

$$
\frac{2}{3} \leq \frac{C C_{T}(\lambda=-1)-C C_{T}(\lambda=0)}{C C_{T}(\lambda=-1)-C C_{T}(\lambda=\infty)} \leq \frac{T}{T+1} .
$$


If in addition the productivity pattern conforms to the one-hoss shay scenario $(\beta=0)$ :

(i) $\lim _{\lambda \rightarrow-1} C C_{T}=\frac{1}{1-\alpha} \cdot \frac{T \cdot h(r)}{(1+r)}$;

(ii) $\lim _{\lambda \rightarrow 0} C C_{T}=\frac{1}{1-\alpha} \cdot \frac{2 \cdot[T \cdot h(r)-1]}{r \cdot(1+T)}$;

(iii) $\lim _{\lambda \rightarrow \infty} C C_{T}=\frac{1}{1-\alpha}$.

Consistent with the observations in Figure 1, Proposition 3 demonstrates that a substantial majority of the drop in $C C_{T}$ as a result of increases in the growth rate occurs in the region where growth rates are negative. At least two-thirds of the reduction, and up to $\frac{T}{T+1}$ of it, takes place as the growth in new investments varies between $-100 \%$ and $0 \%$. The far smaller remainder of the decline occurs when growth varies between $0 \%$ and $\infty$. $^{18}$ Proposition 3 also demonstrates that for extremely negative growth rates, $\lambda \rightarrow-1$, the conservatism correction factor, $C C_{T}$, flattens out and assumes finite limit values, which can be expressed in terms of the annuity function $h(\cdot) .{ }^{19}$ At the other extreme, we find that, again consistent with the observations in Figure $1, C C_{T}$ converges to $\frac{1}{1-\alpha}$ for very high growth rates, irrespective of any of the other parameters.

\section{Hypotheses}

\subsection{Conservatism Correction and Tobin's $q$}

Our decomposition of the market-to-book ratio and our analytical predictions regarding its two principal components have been obtained under specific modeling assumptions. To align the empirical analysis as closely as possible with the above model of accounting conservatism for operating assets, our focus will not be on the ratio defined by the market value of equity over the book value of equity. Instead we shall examine the following adjusted market-tobook ratio:

$$
M B_{T}=\frac{M V_{T}-F A_{T}}{B V_{T}^{o}-F A_{T}},
$$

where $F A_{T}$ denotes financial assets at the observation date $T$. Financial assets here include working capital, such as cash and receivables, net of all liabilities, including both current

\footnotetext{
${ }^{18}$ For general $L>1$, it can be shown that at least half of the drop in $C C_{T}$ occurs in the range of negative growth rates, provided productivity conforms to the one-hoss shay scenario.

${ }^{19}$ This finding can be extended to general values of $\beta$ and $L$. The limit values are available from the authors upon request. We note that $\lim _{\lambda \rightarrow-1} C C_{T}=\frac{b v_{T-1}^{*}}{b v_{T-1}^{o}}$ and $\lim _{\lambda \rightarrow \infty} C C_{T}=\frac{b v_{1}^{*}}{b v_{1}^{o}}$. Here, $b v_{t}^{o} \equiv b v_{t}\left(\mathbf{d}^{o}\right)$.
} 
liabilities and long-term debt. From that perspective, the book value of operating assets is given by $O A_{T}^{o}=B V_{T}^{o}-F A_{T}{ }^{20}$ Given replacement cost accounting, $M V_{T}$ can be expressed as:

$$
M V_{T}=F A_{T}+O A_{T}^{*}+\sum_{t=1}^{\infty}\left[R_{T+t}\left(K_{T+t}(\hat{\mathbf{I}})\right)-c \cdot K_{T+t}(\hat{\mathbf{I}})\right] \cdot \gamma^{t},
$$

in the presence of financial assets. ${ }^{21}$ The adjusted market-to-book ratio therefore can be decomposed into:

$$
M B_{T}=\frac{M V_{T}-F A_{T}}{B V_{T}^{o}-F A_{T}}=C C_{T}+F B_{T},
$$

where

$$
C C_{T}=\frac{O A_{T}^{*}}{O A_{T}^{o}}
$$

and

$$
F B_{T}=\frac{F V_{T}}{O A_{T}^{o}}
$$

As before, the firm's future value, $F V_{T}$, is given by the last term on the right-hand side of (18). We note in passing that the focus on adjusted rather than raw market-to-book ratios makes little difference if the raw market-to-book ratio is close to one.

The conservatism correction factor in (20) can be computed in terms of the firm's investment history, the percentage of investments expensed, the estimated useful life of its investments, and the estimated cost of capital. For our calculation of $C C_{T}$, we assume that the productivity of assets follows the one hoss-shay pattern and that firms rely on straightline depreciation in reporting the value of their capitalized investments. As a consequence, the accounting is uniformly accelerated relative to the unbiased standard of replacement cost accounting, and thus $C C_{T}>1$ by Proposition 1. An explicit formula for $C C_{T}$ is provided in Appendix 1.

From an empirical perspective, it is of interest to examine the magnitude of the residual $M B_{T}-C C_{T}$. This residual is positive whenever our estimate of Tobin's $q$, that is, the ratio

\footnotetext{
${ }^{20}$ We shall from hereon use the more compact notation $B V_{T}^{o}$ instead of $B V_{T}\left(\mathbf{I}_{T}, \mathbf{d}^{o}\right)$. Similarly, we use the shorter $B V_{T}^{*}$ (or $\left.O A_{T}^{*}\right)$ instead of $B V_{T}\left(\mathbf{I}_{T}, \mathbf{d}^{*}\right)$ (or $O A_{T}\left(\mathbf{I}_{T}, \mathbf{d}^{*}\right)$ ).

${ }^{21}$ This representation is, of course, consistent with the studies in Feltham and Ohlson (1995) and Penman, Richardson and Tuna (2007), which presume that financial assets are carried at their fair market values on the balance sheet.
} 
of $M B_{T}$ to $C C_{T}$, is greater than one. One would expect that on average the expected future economic rents are positive.

Hypothesis 1: The residual, $M B_{T}-C C_{T}$, is positive on average.

As argued in connection with Proposition 1, it is conceivable that a firm's future value is negative because past investment decisions, which are irreversible at date $T$, were made with more "exuberant" expectations about future sales revenues than investors hold at the current date $T$. The statement of Hypothesis 1 reflects that such a shift in expectations should not occur on average.

Empirical literature in economics, finance, and accounting continues to use the marketto-book ratio in many contexts. One prominent application is the literature predicting investment. In that context, the market-to-book ratio is commonly viewed as a proxy for Tobin's $q$. The literature on investment generally hypothesizes a linear relation between a firm's current investment and the beginning of year Tobin's $q$, measured as the market value of assets divided by the book value of assets. The motivation for this linear relation is based on models by Modigliani and Miller (1958) and Tobin (1969). Modigliani and Miller argue that investment depends only on investment opportunities. Tobin shows that under certain conditions, investment opportunities are summarized in marginal $q$. Hayashi (1982) establishes conditions under which marginal $q$ is equivalent to average $q$, leading to a linear relation between capital investment in a particular period and Tobin's $q$ at the beginning of that period.

A large number of studies have studied this linear relation, including Fazzari et al (1988, 2000), Kaplan and Zingales (1997), Erickson and Whited (2000), Baker, Stein and Wurgler (2003), Rauh (2006), and McNichols and Stubben (2008). Two notable concerns have been raised in these studies. First, many researchers have commented that the explanatory power of the models is low. ${ }^{22}$ Second, researchers have noted that the poor explanatory power may arise because the market-to-book ratio measures Tobin's $q$ with error. For example, Poterba (1988) notes: "There are many reasons for suspecting measured $Q$ is not a sufficient statistic for future cash flows. These range from difficulties in measuring the replacement cost of a firm's assets, to concern over whether average $Q$ is a good proxy for marginal $Q$ to questions about the incremental content of stock prices themselves."

Lindenberg and Ross (1981) use replacement cost data disclosed in 10-K filings in 1976 and 1977 to estimate $q .{ }^{23}$ Subsequent studies, such as Lewellen and Badrinath (1997), have

\footnotetext{
${ }^{22}$ See, for example, the discussion by Erickson and Whited (2000), p. 1029.

${ }^{23}$ Lindenberg and Ross did not test whether this improved their measure of $q$, and the SEC subsequently abandoned the requirement to disclose replacement cost of property and plant.
} 
sought to improve upon the original approach taken by Lindenberg and Ross for estimating the replacement cost value of assets in place. In the context of our model, it is natural to ask whether the inclusion of the conservatism correction factor, $C C_{T}$, will lead to improved specifications for investment models. To that end, we hypothesize that, after controlling for the market-to-book ratio, $C C_{T}$ will be negatively associated with investment. If our measure of conservatism captures the difference between replacement cost and book value of operating assets, we would expect future investment to be decreasing in $C C_{T}$ after controlling for $M B_{T}$. Intuitively, a firm will invest less than would be predicted by $M B_{T}$ if this ratio is inflated because the denominator understates the replacement cost of assets.

Hypothesis 2: Controlling for the current market-to-book ratio, $M B_{T}$, next period's investment is a decreasing function of the conservatism correction factor, $C C_{T}$.

Our test of Hypothesis 2 provides evidence on whether the conservatism correction factor has explanatory power for investment. Our next prediction is based on our measure of $q$ obtained as the ratio of $M B_{T}$ to $C C_{T}$. We hypothesize that this measure of $q$ better explains investment than the market-to-book ratio. The competing measures are incorporated in competing (non nested) models to explain investment.

Hypothesis 3: In comparison to the current Market-to-Book ratio, $M B_{T}$, our measure of Tobin's q, given by $\frac{M B_{T}}{C C_{T}}$, has greater explanatory power for next period's investment.

Our test of Hypothesis 3 applies the Vuong (1989) statistic to determine which model is closer to the true model explaining investment.

\subsection{Predictions for the conservatism correction factor}

For further validation of our model and our conservatism correction construct, we now develop an independent estimate of the future-to-book ratio $F B_{T}$. Denoting this estimate by $\hat{F B_{T}}$, we can rely on the additive decomposition of the market-to-book ratio into $C C_{T}$ and $F B_{T}$ to obtain the estimated conservatism correction factor:

$$
\hat{C C_{T}}=M B_{T}-\hat{F B} B_{T}
$$

We recall that in our model future value captures the stream of expected future discounted economic profits, that is, the stream of residual income numbers that emerge under the replacement cost depreciation rule. As such, it combines the firm's investment history with future decisions to be made optimally. One way to estimate $F B_{T}$ therefore is to extrapolate 
the current economic profit at date $T$. We adopt an asymmetric specification that takes a capitalization of the current economic profit as the estimated future value, provided current economic profit is positive. In contrast, our measure of estimated future value is set equal to zero if current economic profit is negative. This specification reflects that, given optimal future investments, firms ought to be able to revert back to non-negative economic profits over time. ${ }^{24}$ Formally, we define the estimated future-to-book ratio as:

$$
\hat{F B_{T}}=\frac{\mathcal{I}\left\{R_{T}\left(K_{T}\right)-c \cdot K_{T}-\tau_{T} \cdot\left(R_{T}\left(K_{T}\right)-\operatorname{Exp}_{T}\right)\right\} \cdot \Gamma_{\lambda}^{5}}{O A_{T}^{o}},
$$

where $\tau_{T}$ is the statutory income tax rate in year $T, \operatorname{Exp}_{T}$ represents expenses in year $T$ and $\mathcal{I}\{x\}$ is the indicator function corresponding to a call option, that is, $\mathcal{I}\{x\}=x$ if $x \geq 0$, while $\mathcal{I}(x)=0$ if $x \leq 0 .{ }^{25}$ The expression inside the indicator function represents the firm's economic income at date $T$ on an after-tax basis. Finally, the "capitalization" factor $\Gamma_{\lambda}^{5}$ is given by $\sum_{i=1}^{5}\left(\frac{1+\lambda_{3}^{a}}{1+r}\right)^{i}$, where $\lambda_{3}^{a}$ denotes the geometric mean of investment growth over the past 3 years. ${ }^{26}$ Since the economic profit $R_{T}\left(K_{T}\right)-c \cdot K_{T}$ is not observable, we estimate this number by making suitable adjustments to the firm's accounting income, based on Rajan and Reichelstein (2009). The details of this adjustment are described in the next section summarizing our empirical findings.

If our measures of the conservatism correction and the estimated future-to-book ratio indeed provide a reasonable approximation of the underlying constructs, we would expect both $\hat{F B} B_{T}$ and $C C_{T}$ to have significant explanatory power for the overall market-to-book ratio $M B_{T}$.

\section{Hypothesis 4: Both $C C_{T}$ and $\hat{F B_{T}}$ have significant explanatory power for $M B_{T}$.}

We next formulate several hypotheses related to accounting conservatism and past growth. The predicted impact of higher growth rates in past investments on the $M B_{T}$ ratio is ambiguous in our model. While the predicted impact on $C C_{T}$ is unambiguous according to Proposition 1, both the numerator and the denominator in $F B_{T}$ are likely to increase with higher growth rates in the past. To the extent that $\hat{F B_{T}}$ provides a suitable proxy for $F B_{T}$, we would therefore expect $\hat{C C_{T}}$ to be decreasing in past investment growth. Furthermore,

\footnotetext{
${ }^{24}$ It goes without saying that our approach to forecasting future value is somewhat ad hoc. There appear to be many promising avenues for refining the approach taken here in future studies.

${ }^{25}$ Our approach of incorporating income taxes avoids the issues of estimating the firm's actual tax rate or taxes to be paid in future periods.

${ }^{26}$ Our capitalization of current economic profit is broadly consistent with the valuation model developed in Nezlobin (2012). We use the average growth rate over the past three years as a proxy for anticipated future growth in the firm's product markets.
} 
Corollary 1 shows that the negative impact of past growth on the conservatism correction factor is stronger for firms that expense a larger percentage of their investments.

Hypothesis 5: (i) $\hat{C C}_{T}$ is decreasing in past investment growth. (ii) This negative association is more pronounced for firms with a higher percentage of intangibles investments.

Proposition 3 shows that the drop in $C C_{T}$ as a function of past investment growth is far more pronounced for firms with negative growth rates compared to those with positive growth rates. Figure 1 also illustrates this pattern. This leads to the following:

Hypothesis 6: The negative association between $\hat{C C}_{T}$ and past investment growth is more pronounced for firms with negative average growth in past investments than for firms with positive average growth in past investments.

As observed in Section 2, a firm's future value, $F V_{T}$, should ceteris paribus be decreasing in the cost of capital $r$, simply because future free cash flows are discounted at a higher rate. Yet the scenario of a firm operating under competitive conditions provides a good illustration of why such a ceteris paribus approach is likely to be misleading. A firm operating in a competitive environment will obtain revenues that match its entire economic cost. Therefore a higher discount rate must lead to both higher capital costs and corresponding higher sales revenues. The impact of changes in $r$ on the Market-to-Book ratio then reduces to the impact of $r$ on the Conservatism Correction factor. Proposition 2 established that a higher cost of capital will generally result in a higher replacement cost for the firm's current assets, that is, a higher value $O A_{T}^{*}$. Accordingly, we formulate the following:

Hypothesis 7: $\hat{C C}_{T}$ is increasing in the cost of capital, $r$.

\section{Empirical analysis}

Our empirical analysis is designed to test the implications of the model, using a cross-section of firms over time. Section 4.1 discusses our empirical proxies for the theoretical constructs, Section 4.2 describes sample formation, while the empirical methodology and the results are reported in Section 4.3. Finally, we provide a summary of our sensitivity analysis in Section 4.4 . 


\subsection{Empirical Proxies for Key Constructs}

The key variables in our analysis of the market-to-book ratio, $M B_{T}$, are the useful life of assets, $T$, growth in investments, $\left(\lambda_{1}, . ., \lambda_{T}\right)$, the depreciation schedule $\mathbf{d}$, the percentage of intangibles investments, $\alpha_{T}$, and the cost of capital, $r_{T}$. These variables jointly determine the two principal components of the market-to-book ratio: $C C_{T}$ and $F B_{T}$. In this section, we describe our proxies for these constructs and the assumptions underlying their use. The Compustat Xpressfeed variable names used in our measures are presented parenthetically. Additional details on the measurement of these and related variables are included in Appendix 1.

As discussed in Section 3, we focus on the adjusted market-to-book ratio, which effectively excludes financial assets, as these are not subject to the forms of conservatism we study in this paper. The market value of equity and book value of equity are measured at the end of the fiscal year. The useful life of tangible and intangible assets, denoted as $T$ throughout the model, is measured by taking the sum of the gross amount of property, plant, and equipment and recognized intangibles, divided by the annual charge for depreciation $\frac{P P E G T+I N T A N}{d p}$. The depreciation variable on Compustat, $d p$, includes amortization of intangibles. Although our measure is admittedly an approximation, it provides an estimate of the weighted average useful life of the capitalized operating assets of the firm. This measure does not include investments that are immediately expensed such as R\&D and advertising expense; effectively this assumes the omitted assets have a useful life comparable to the recognized assets.

Total investments in the observation year, $T$, are denoted by $I N V_{T}$. This value is calculated as research and development expenses (XRD) plus advertising expenses (XAD) plus capital expenditures (CAPXV). Growth in investment in a given period, $\lambda_{T}$, is calculated as

$$
\frac{I N V_{T}}{I N V_{T-1}}-1
$$

We also compute the average growth rate over the past $T$ periods by the geometric mean of the rates $\left(\lambda_{1}, \ldots, \lambda_{T}\right)$.

The model captures two forms of unconditional conservatism: partial expensing of assets and conservatism in depreciation. Our measure of partial expensing, $\alpha_{T}$, is the ratio of research and development expenses and advertising expenses to total investment, that is, $\frac{X R D+X A D}{X R D+X A D+C A P X V}$. Although there are alternative measures of conservatism in the empirical accounting literature, $\alpha_{T}$ reflects our construct of partial expensing and is therefore consistent with our theory framework.

Since our analysis is focused on operating assets and the effects of conservatism in measuring those assets, we seek to measure the firm's cost of capital by estimating its weighted 
average cost of capital. Accordingly, we take an "operating" approach in implementing the residual income formula in (18). Specifically, interest is excluded from the calculation of income, and the residual interest charge is based on the weighted average cost of capital and the replacement value of operating assets. The question of how to measure the equity cost of capital, $r_{T}$, is certainly not without controversy in the accounting and finance literature. In order to obtain an equity cost of capital measure that does not rely on financial statement numbers, we rely on the Fama and French (1992) two-factor approach with the market return and firm size as factors. If the firm's implied cost of capital is missing or negative, we substitute the median cost of capital for firms in the same two-digit SIC code and year.

As indicated in Section 3, we estimate the future-to-book ratio at date $T, F B_{T}$, by capitalizing the firm's current economic profit net of taxes, provided that profit measure is positive. In turn, we obtain an approximation of the firm's current economic profit, $R_{T}\left(K_{T}\right)-c \cdot K_{T}$, by current residual income, subject to a correction factor, $\Delta_{T}$, based on the model in Rajan and Reichelstein (2009). This correction is intended to adjust for the biases that result from the direct expensing of intangibles investments and the use of straight-line depreciation. Specifically, our proxy for $R_{T}\left(K_{T}\right)-c \cdot K_{T}$ is $\operatorname{Sales}_{T}-$ EconCost $_{T}$ where:

$$
\text { EconCost }_{T}=\text { Expenses }_{T}-\operatorname{dep}_{T}+\frac{1}{\Delta_{T}} \cdot\left(\operatorname{dep}_{T}+r \cdot O A_{T-1}^{o}\right) .
$$

Here $r$ denotes the weighted average cost of capital and the correction factor $\Delta_{T}$ is given by: $:^{27}$

$$
\Delta_{T}=\Gamma^{T} \cdot \frac{u_{0}+u_{1}\left(1+\lambda_{1}\right)+\cdots+u_{T-1} \prod_{i=1}^{T-1}\left(1+\lambda_{i}\right)+\alpha_{T} \cdot \prod_{i=1}^{T}\left(1+\lambda_{i}\right)}{1+\left(1+\lambda_{1}\right)+\cdots+\prod_{i=1}^{T-1}\left(1+\lambda_{i}\right)},
$$

where

$$
\Gamma^{T}=\frac{1}{1+r}+\left(\frac{1}{1+r}\right)^{2}+\ldots+\left(\frac{1}{1+r}\right)^{T}
$$

and

$$
u_{t}=\left(1-\alpha_{t}\right)\left[\frac{1}{T}+r \cdot\left(1-\frac{T-1-t}{T}\right)\right]
$$

for $0 \leq t \leq T-1$. The correction factor $\Delta_{T}$ is the ratio of two historical cost figures: the numerator represents the historical cost obtained with direct expensing for investments in

\footnotetext{
${ }^{27}$ Throughout our empirical analysis, we set the lag factor $L$ equal to 1 . It seems plausible that there are significant variations in $L$ across industries, an aspect we do not pursue in this paper.
} 
intangibles and straight-line depreciation of all capitalized investments; the denominator is given by the historical (economic) cost under replacement cost accounting. This correction is applied to operating assets and is based on the weighted average cost of capital $r$. The correction factor $\Delta_{T}$ exceeds (is below) one whenever the past growth rates have consistently been below (above) the cost of capital, that is, $\lambda_{t} \leq(\geq) r$ for all $t$.

\subsection{Sample selection}

Our empirical tests employ financial statement data from Compustat Xpressfeed and cost of capital data from the CRSP monthly returns file and Ken French's website on return factors. Our sample covers all firm-year observations with available Compustat data and covers the time period from 1962 to 2007. We exclude firm-year observations with SIC codes in the range 6000-6999 (financial companies) because the magnitude of these firms' financial assets likely precludes our detecting the effects on market-to-book we are interested in. This gives us a starting point of 316,896 firm-year observations, as indicated in Table 1. We impose several additional criteria to insure firms have the relevant data to measure the variables in our analysis. Specifically, we exclude observations for which market value is not available (94,185 firm-years), book value of operating assets is not available (582 firmyears), market value of net operating assets is zero or negative (13,831 firm-years), there is insufficient history for the calculation of $C C_{T}$ (37,106 firm-years), the ratio of plant to total assets is less than $10 \%$ (28,859 firm-years), and total assets are less than $\$ 4$ million $(6,978)$. These criteria yield a sample size of 135,358 firm-year observations with data on the primary variables we examine. The number of observations in any given regression varies depending on the availability of additional data necessary for the particular test as well as deletion based on outlier diagnostics.

\subsection{Empirical methodology and results}

We report results based on pooled OLS regressions. The standard errors we report are adjusted for cross-sectional and time-series dependence, using the approach recommended by Peterson (2009) and Gow, Ormazabal and Taylor (2010). To minimize the influence of extreme observations in the parametric regressions, we winsorize included variables at the second and 98th percentile and exclude observations using deletion filters based on the outlier diagnostics of Belsey, Kuh and Welsch (1980). In addition, we estimate a second set of regressions where the continuous value of the independent variable is replaced with its annual percentile rank. To create these ranks, the continuous variables are sorted annually into 100 equal-sized groups. This second set of regressions makes the less restrictive assumption that 
the relations between the dependent and explanatory variables are monotonic (Iman and Conover 1979). In the interests of parsimony, we present the parametric estimations in the tables and report the nonparametric estimations only when they differ from the parametric results.

\section{Descriptive statistics}

Table 2 presents the descriptive statistics for our sample. The average market-to-book ratio is 2.49, and the median is 1.62 . The median and skewness of the distribution are consistent with the data in Penman (2009, p. 43). For the adjusted market-to-book ratio, $M B_{T}$, we observe an average market-to-book ratio for operating assets of 3.023, consistent with our presumption that financial assets have book values closer to their market values. The median value for the weighted average cost of capital is $11.5 \%$, which is consistent with the leverage ratios and average return on equities for the period 1962-2007 (Ibbotson and Associates 2006). The average capital intensity, measured as plant to total assets, is $39.4 \%$, confirming that plant assets are material for our sample. Advertising intensity and R\&D intensity are skewed, with zero expense recognized at the 25 th and 50 th percentiles. The average useful life of plant and capitalized intangibles is 14.791 , with a median of 14 . The average (untabulated) annual fraction of partial expensing is $23.4 \%$, with a median of $7.8 \%$, and the growth-weighted average measure, $\alpha_{T}^{a}$, is $20.5 \%$ with a median of $8.1 \%$, consistent with skewness in advertising and R\&D. The geometric mean of $\lambda_{T}^{a}$ is $22.5 \%$.

The mean of $C C_{T}$ is 1.865 , and the median is 1.367. As a result, the mean of $F B_{T}$, defined as the residual $M B_{T}-C C_{T}$, is 1.158. The sizable magnitude of $C C_{T}$ and $F B_{T}$ suggests that both conservatism and future value are substantial components of $M B_{T}$. The mean of $C C_{T}^{\lambda}$ is 1.897 with a median of 1.334 . Thus the calculation of the conservatism correction factor based on a measure of the average constant growth over the past $T$ periods results in a conservatism correction of similar magnitude to that based on the full history of investments over the prior $\mathrm{T}$ periods. The variable $\hat{F B} B_{T}$ in Table 2 is an estimate of future value based on estimated future economic profits. We note that $\hat{F B_{T}}$ has a mean of 1.208 and a median of 0.000 and thus is fairly comparable to the measure of $F B_{T}$ derived by subtracting $C C_{T}$ from $M B_{T}$. Panel $\mathrm{B}$ of Table 2 presents a correlation matrix of the variables, with Pearson correlations above the diagonal and Spearman correlations below the diagonal. The correlations provide support for a number of our measures and constructs.

\section{Tests of hypotheses}

Our first hypothesis is that $F B_{T} \equiv M B_{T}-C C_{T}$ is positive on average. This is motivated by the postulate that economic profits resulting from past investments should be non negative 
on average. As documented in Table 3, the mean of $F B_{T}$ is positive. The t-statistic for the hypothesis that the mean of $F B_{T}$ exceeds 0 equals 10.13 and is highly significant.

To test Hypotheses 2 and 3 concerning the relation between current investment, the lagged market-to-book ratio and our measure of Tobin's $q$, we begin with the regression equation examined in earlier studies: ${ }^{28}$

$$
C A P X V_{T+1}^{\prime}=\eta_{01}+\eta_{11} \cdot M B_{T}+\epsilon_{1}
$$

Here, $C A P X V_{T+1}^{\prime}$ denotes capital expenditures in period $T+1$ normalized by current operating assets. In our notation:

$$
C A P X V_{T+1}^{\prime} \equiv \frac{C A P X V_{T+1}}{O A_{T+1}^{o}} .
$$

Hypothesis 2 states that the conservatism correction factor $C C_{T}$ has additional explanatory power for predicting next period's investment and that furthermore the coefficient on $C C_{T}$ in the equation:

$$
C A P X V_{T+1}^{\prime}=\eta_{01}^{\prime}+\eta_{11}^{\prime} \cdot M B_{T}+\eta_{21}^{\prime} \cdot C C_{T}+\epsilon_{1}^{\prime}
$$

will be negative. The results reported in column E1 of Table 4, Panel A, strongly reject the null hypothesis that $C C_{T}$ does not have explanatory power for investment choice.

We next consider our measure of Tobin's $q$, that is:

$$
q_{T} \equiv \frac{M B_{T}}{C C_{T}}
$$

as an alternative explanatory variable for future investment. Column E2 of Panel B in Table 4 shows the results of regressing next period's investment on $q_{T}$.

$$
C A P X V_{T+1}^{\prime}=\eta_{02}+\eta_{12} \cdot q_{T}+\epsilon_{2}
$$

The findings indicate that our measure of Tobin's $q$ is significantly associated with future investment, with an adjusted $R^{2}$ of $18 \%$ for model E2, compared to an adjusted $R^{2}$ of $13.4 \%$ for model E1. Finally, we conduct a "horse race" between the market-to-book ratio and our measure of Tobin's $q$ to assess which variable has the greater predictive power for next period's investment. To that end, we perform a Vuong (1989) test of non-nested alternatives. The results, reported in Panel B of Table 4, strongly favor our measure of Tobin's $q$ over the unadjusted market-to-book ratio. We conclude that applying our conservatism correction

\footnotetext{
${ }^{28}$ See, for instance, Fazzari et al. (1988, 2000), Kaplan and Zingales (1997, 2000), Erickson and Whited (2000), Baker, Stein and Wurgler (2003), Rauh (2006), and McNichols and Stubben (2008).
} 
results in a model of investment that is closer to the true model than the investment model widely applied in earlier accounting, economics and finance studies.

Our fourth hypothesis is that both $\hat{F B} B_{T}$ and $C C_{T}$ have significant explanatory power for $M B_{T}$. The test of this hypothesis is based on the estimation equation:

$$
M B_{T}=\eta_{03}+\eta_{13} \cdot C C_{T}+\eta_{23} \cdot \hat{F B} B_{T}+\epsilon_{3}
$$

We hypothesize positive coefficients on both $C C_{T}$ and $\hat{F B} B_{T}$. Table 5 presents the estimation results, indicating that both $C C_{T}$ and $\hat{F B_{T}}$ have significant explanatory power for $M B_{T}$. The coefficient on $C C_{T}$ is 0.716 with a t-statistic of 23.45 . The coefficient on $\hat{F B_{T}}$ is 0.274 , with a t-statistic of 22.12. Including both variables in the estimation causes the adjusted $R^{2}$ to climb from $12.2 \%$ and $12.9 \%$ for the single variable regressions to $24.4 \%$, consistent with both variables having significant incremental explanatory power. The findings indicate that both our conservatism correction factor and our estimate of future value explain a substantial part of the variation in $M B_{T}$.

In our model, the market-to-book ratio is a hyperbolic function of $\alpha$, the percentage of new investments directly expensed, since asset values in the denominator of $M B_{T}$ are scaled down by the factor $1-\alpha$. Figure 2 presents the graph of market-to-book values plotted against $\alpha_{T}^{a}$, confirming a convex relationship. Panel A of Table 6 displays the values of $\alpha_{T}^{a}$ partitioned by half-deciles and the corresponding value of $M B_{T}$ for each partition. Because many firms do not report advertising or research and development expense to Compustat and therefore $\alpha=0$, a sizable number are pooled in the bottom 6 ranks (0-5). The mean $M B_{T}$ for these firms is 2.242. For observations with positive values of $\alpha, M B_{T}$ increases monotonically in $\alpha_{T}^{a}$, ranging from 1.876 for the partition with mean $\alpha_{T}^{a}=0.001$ to 7.993 for observations with $\alpha_{T}^{a}=0.798$.

To illustrate the hyperbolic relationship between $M B_{T}$ and $\alpha$, we examine whether the natural logarithm of the Market-to-Book ratio is negatively associated with the logarithm of $1-\alpha$. The corresponding estimation equation is:

$$
\ln \left(M B_{T}\right)=\eta_{04}+\eta_{14} \cdot \ln \left(1-\alpha_{T}^{a}\right)+\epsilon_{4} .
$$

Our results in Panel B of Table 6 document that the relation between the $\log$ of $M B_{T}$ and $\log \left(1-\alpha_{T}^{a}\right)$ is highly significantly negative, with a coefficient estimate of -0.846 and t-statistic of -29.94 .

Our fifth hypothesis concerns the relation between $C C_{T}$ and past investment growth. In addition to our prediction that past growth has a negative impact on $C C_{T}$, this negative association should be accentuated for firms that expense a larger percentage of their 


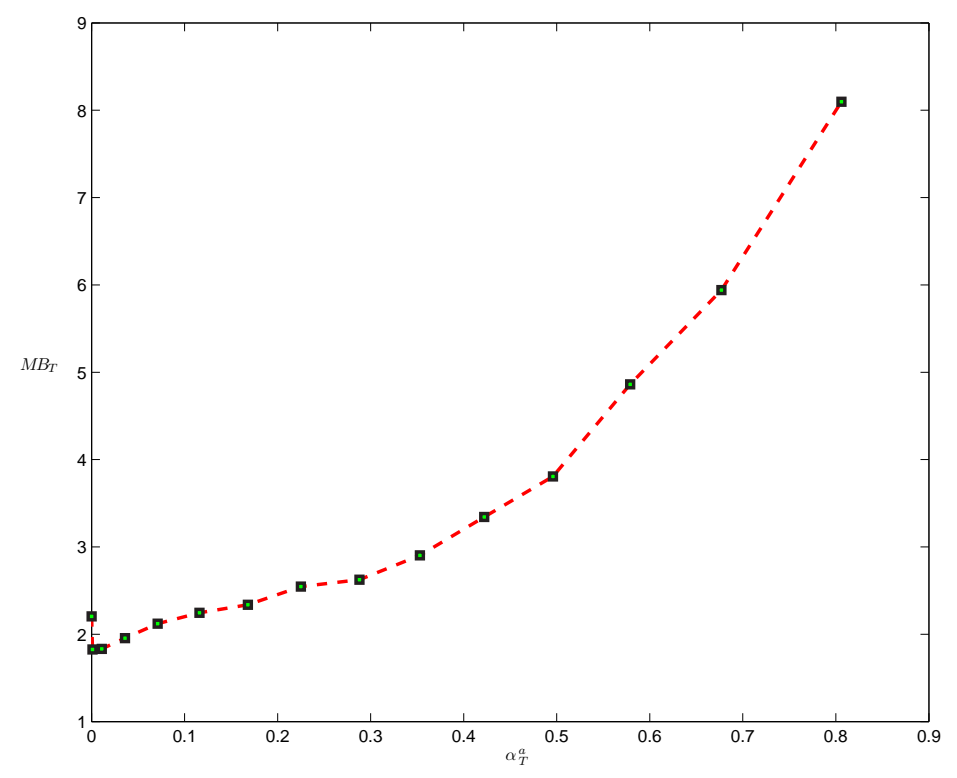

Figure 2: Market-to-book as a function of the percentage of investments directly expensed.

investments (Corollary 1). ${ }^{29}$ We base our inferences about Hypothesis 5 on the following estimation equation:

$$
\hat{C C_{T}}=\eta_{05}+\eta_{15} \cdot \alpha_{T}^{a}+\eta_{25} \cdot \lambda_{T}^{a}+\eta_{35} \cdot r_{T}+\epsilon_{5} .
$$

Panel A of Table 7 presents the values of $M B_{T}, C C_{T}, F B_{T}$, and their estimated counterparts: $\hat{F B_{T}}$ and $\hat{C C_{T}} \equiv M B_{T}-\hat{F B_{T}}$, partitioned by half-deciles of average growth, $\lambda_{T}^{a}$. The findings indicate a largely declining relation between the market-to-book ratio and growth for the first five half-deciles and then an increasing relation. In contrast, our estimate of the future-to-book ratio based on $\hat{F B} B_{T}$ is strictly increasing in past investment growth, consistent with the notion that investment increases in response to greater profit opportunities. The positive relation between future value and growth thus offsets the hypothesized negative relation between $C C_{T}$ and investment growth. As discussed earlier, we therefore test for a negative relation between $\hat{C C_{T}}$ and $\lambda_{T}^{a}$ to control for the opposing relation between $F B_{T}$ and $\lambda_{T}^{a}$. Column (1) of Panel B in Table 7 shows that the coefficient on $\lambda_{T}^{a}$ is significantly negative. This finding therefore supports Hypothesis 5, which postulates that the conservatism correction component of the market-to-book ratio is decreasing in past growth. ${ }^{30}$

\footnotetext{
${ }^{29}$ It should be recalled at this stage that our framework allows for only a single category of operating assets and correspondingly growth in one dimension. Zhang (1998) considers the impact of differential growth rates for PPE and intangible assets.

${ }^{30} \mathrm{~A}$ caveat to this interpretation is that measurement error in our estimate of $\hat{F B} B_{T}$ is not highly correlated
} 
With regard to part (ii) of Hypothesis 5, we compare the coefficient on $\lambda_{T}^{a}$ for observations with $\alpha_{T}^{a}$ above versus those below the median. The larger negative (absolute value) coefficients for firms with a high proportion of intangibles emerges both in the parametric and nonparametric (ranks) regressions. One peculiarity in the parametric estimation results is that the coefficient on $\alpha_{T}^{a}$ turns negative for the subsample with low values of $\alpha_{T}^{a}$. This may reflect the relatively lower power of the test resulting from the limited variation in $\alpha_{T}^{a}$ inherent in that subsample. Notably, the coefficient on $\alpha_{T}^{a}$ is positive, though insignificant, in the nonparametric results.

Hypothesis 6 is derived from our analytical finding in Proposition 3: the decline in $C C_{T}$ is more pronounced for firms with negative past growth in investments than for those with positive average growth. Put differently, $C C_{T}$ is a monotonically decreasing function of $\lambda_{T}^{a}$, but the function flattens out for larger values of $\lambda_{T}^{a}$. In testing this prediction, we employ the same regression equation as before, except that the variable $\lambda_{T}^{a}$ is partitioned into two subsamples depending on whether average past growth was positive or negative. The two corresponding variables are denoted by $\lambda_{T}^{a-}$ and $\lambda_{T}^{a+}$, respectively.

$$
\hat{C C_{T}}=\eta_{05}^{\prime}+\eta_{15}^{\prime} \cdot \alpha_{T}^{a}+\eta_{25}^{\prime} \cdot \lambda_{T}^{a+}+\eta_{35}^{\prime} \cdot \lambda_{T}^{a-}+\eta_{45}^{\prime} \cdot r_{T}+\epsilon_{5}^{\prime}
$$

Our findings in Panel $\mathrm{C}$ of Table 7 suggest a more negative association between past growth in investments and the estimated conservatism correction factor on account of two forces: (i) negative growth, that is $\lambda_{T}^{a}<0$, and (ii) a high percentage of intangibles investments $\alpha_{T}^{a}$. This relation holds in the parametric estimation for the subsample of firms with high intangibles but not for the sample overall. The nonparametric estimation results indicate that the decline in the estimated conservatism correction factor is greater for firms with negative past growth in investments than for those with positive average growth, and this relation is more pronounced for firms with a higher percentage of intangibles investments.

Our final hypothesis speaks to the relation between $C C_{T}$ and the weighted average cost of capital, $r_{T}$. We test whether the component of $C C_{T}$ embedded in $M B_{T}$ has a positive relation to the cost of capital. Accordingly, we again consider $\hat{C C_{T}} \equiv M B_{T}-\hat{F B_{T}}$ as our dependent variable. Our test of Hypothesis 7 is that the coefficient on $r_{T}$ in estimation equation E5 is positive. The findings in Panels B and C of Table 7 indicate strong support for this hypothesis. The coefficient on $r_{T}$ is positive and significant in all specifications. These findings are not due to induced measurement error in our estimate of future value, as

with past growth. To the extent such a correlation arises, it could induce a negative correlation between $\hat{C C_{T}}$ and past growth. We do not expect that this is driving our results as the correlation between $\hat{C C_{T}}$ and past growth is largely comparable to the correlation between $C C_{T}$ and past growth. 
the correlation matrix in Table 2 Panel B indicates a significant positive correlation between $M B_{T}$ and $r_{T}$ as well.

\subsection{Sensitivity analysis}

In addition to the tabulated results, we conducted a number of sensitivity analyses. These include estimating all the regression models tabulated in the paper using rank regressions to provide assurance that unusual observations did not overly influence our results. We also incorporated additional controls in our primary models to insure our findings were not due to omitted variables. Specifically, we included $\lambda, \alpha$, and $r$ in equation E5.

We also examined the sensitivity to alternative measures of model parameters such as measuring growth over shorter or longer windows, and measuring cost of capital using solely cost of equity versus the weighted average cost of capital. Next, we analyzed the effects of alternative winsorizing techniques, such as $1 \%$ and $99 \%$ rather than the $2 \%$ and $98 \%$ reported in the tables. We also examined whether our results are sensitive to inclusion of firms with plant less than $10 \%$ of total assets or total assets less than $\$ 4$ million. In addition, we incorporated analysts' forecasts of future earnings and future earnings growth to measure future value and then re-estimated equations E3 and E5. The alternate specification for E5 allows us to assess whether the negative coefficient on $\lambda$ is related to its inclusion in future value and therefore our measure of implied conservatism correction, $\hat{C C}$. Finally, we analyzed whether our investment results were sensitive to the measurement of our dependent variable, by measuring investment deflated by conservatism-corrected operating assets rather than historical cost. The Vuong z-statistic indicating a preference for the conservatismcorrected market-to-book ratio, that is, our measure of Tobin's $q$, is -75.78. In summary, our conclusions are not sensitive to any of the variations in methods we have examined.

\section{Conclusion}

This paper proposes an additive decomposition of the market-to-book ratio into two component ratios: the conservatism correction factor $(\mathrm{CC})$ and the future-to-book ratio $(\mathrm{FB})$. By construction, the CC factor exceeds one if the firm's operating assets are valued below their

replacement cost on the balance sheet. A positive FB ratio reflects investors' expectation of a stream of positive (discounted) future economic profits.

Our empirical findings indicate that the conservatism correction factor is significantly greater than one, with a mean of 1.865 , and the future-to-book ratio is significantly positive, with a mean of 1.158. Given that the mean market-to-book ratio for our sample is 3.023, 
these findings suggest that each component is significant in explaining a market-to-book ratio greater than one. Our regression of the market-to-book ratio on the conservatism correction factor and the estimated future value shows that each component indeed has significant explanatory power for the market-to-book ratio, with an adjusted $R^{2}$ of $24.4 \%$ for the combined model.

Our decomposition allows us to operationalize Tobin's $q$ because the $q$ of an all-equity firm's is given by the ratio of the market-to-book ratio to the conservatism correction factor. This observation becomes the basis for revisiting the statistical relation between a firm's market-to-book ratio and its future investments. As one would expect, we find that, given the market-to-book ratio as an explanatory variable, a higher conservatism correction factor is associated with lower levels of future investment. We also find strong support for the hypothesis that our derived measure of Tobin's $q$ is superior to the market-to-book ratio in its ability to predict future investment.

The model developed in this paper predicts that the conservatism correction factor ratio is decreasing in past investment growth. We document a significant negative relation between $\hat{C C_{T}}$ and past growth, and, consistent with the theoretical predictions, also find a steeper negative relation for firms with a greater percentage of investments in intangibles. In addition, we predict and find that the association between market-to-book and past investment growth is more pronounced for firms with negative average growth in past investments than positive past growth. Lastly, we predict and find that the conservatism correction factor embedded in the market-to-book ratio is positively related to the cost of capital. We document this relation both for the implied conservatism correction factor and for the overall market-to-book ratio. Taken as a whole, the evidence presented supports the predictions of the model and documents its potential to improve specifications in empirical studies that currently use the market-to-book ratio. 


\section{Appendix 1 - Tables}

\section{Description of variables}

$$
\begin{aligned}
& M V_{T} \quad=\text { Market value of equity at end of fiscal year T }\left(C S H O * P R C C_{-} F\right) \\
& M B_{T}^{u n} \quad=\quad \text { Market value of equity at time } T \text { divided by book value of equity for } \\
& \text { fiscal year } T \\
& F A_{T} \quad=\text { Net financial assets at end of fiscal year } t \text {, measured as total assets } \\
& \text { minus net plant and intangibles minus liabilities (AT - PPENT - } \\
& \text { INTAN-LT) } \\
& M B_{T} \quad=\frac{M V_{T}-F A_{T}}{O A_{T}^{o}}=\frac{M V_{T}-F A_{T}}{B V_{T}^{o}-F A_{T}} \text {. Adjusted Market-to-Book ratio } \\
& O A_{T}^{o} \quad=\text { Net plant }+ \text { intangibles, at end of fiscal year } T,(P P E N T+I N T A N) \\
& \text { Total In- }=\text { Advertising expense plus } \mathrm{R} \& \mathrm{D} \text { expense plus Capital expenditures } \\
& \text { vestment for period } T-1 \text { to } T(X A D+X R D+C A P X V) \\
& \text { OIADP }=\text { Operating income after depreciation, amortization } \\
& \text { Expenses }=\text { SALE - OIADP } \\
& \alpha_{t} \quad=\text { Conservatism in fiscal year } t \text {, measured as }(X A D+X R D) /(X A D+ \\
& X R D+C A P X V) \text {, where } X A D \text { is advertising expense; } X R D \\
& \text { is Research and Development expense; and } C A P X V \text { is capital } \\
& \text { expenditures } \\
& \alpha_{T}^{a} \quad=\text { Growth weighted average of directly expensed investments } \\
& \frac{\alpha_{1}\left(1+\lambda_{1}\right)+\cdots+\alpha_{T} \prod_{i=1}^{T}\left(1+\lambda_{i}\right)}{\left(1+\lambda_{1}\right)+\cdots+\prod_{i=1}^{T}\left(1+\lambda_{i}\right)} \\
& T=\text { useful life of plant and intangibles, } \\
& \text { (averagegross plant }+ \text { intangibles)/(depreciation }+ \text { amortization of intangibles) } \\
& \text { measured as (averagePPEGT + INTAN)/dep } \\
& \lambda_{t} \quad=\frac{X A D_{t}+X R D_{t}+C A P X V_{t}}{X A D_{t-1}+X R D_{t-1}+C A P X V_{t-1}}-1 \\
& \lambda_{T}^{a} \quad=\text { Geometric mean of growth over } T \text { periods } \\
& \lambda_{3}^{a}=\text { Geometric mean of growth rates }\left(\lambda_{T}, \lambda_{T-1}, \lambda_{T-2}\right)
\end{aligned}
$$


$r_{e} \quad=$ Equity cost of capital for firm $i$ and year $T$, estimated with coefficients from the Fama-French (1992) two-factor model:

$R_{i}-R_{f}=\delta_{0}+\delta_{1}\left(R_{m}-R_{f}\right)+\delta_{2}(S M B)+\epsilon$

using CRSP monthly returns from five preceding years and Ken

French's data on market and size factors (SMB)

$\tau_{T} \quad=$ Statutory income tax rate in year $T$

$r_{d} \quad=$ Cost of Debt: $\left(1-\tau_{T}\right)$. Interest Expense divided by the average of beginning and ending balance of interest-bearing debt

$r \quad=$ Weighted average cost of capital: $\frac{B V_{T}^{o}}{A T_{T}^{o}} \cdot r_{e}+\frac{A T_{T}^{o}-B V_{T}^{o}}{A T_{T}^{o}} \cdot r_{d} \cdot\left(1-\tau_{T}\right)$

$\Gamma^{n} \quad \equiv \gamma+\gamma^{2}+\ldots \gamma^{n}$

$N_{T} \quad=\Gamma^{1}+\Gamma^{2}\left(1+\lambda_{2}\right)+\ldots \Gamma^{T} \prod_{i=2}^{T}\left(1+\lambda_{i}\right)$

$D_{T} \quad=\left(1-\alpha_{1}\right)\left(1-\frac{T-1}{T}\right)+\left(1-\alpha_{2}\right)\left(1-\frac{T-2}{T}\right)\left(1+\lambda_{2}\right)+\ldots$

$\left(1-\alpha_{T-1}\right) \prod_{i=2}^{T-1}\left(1+\lambda_{i}\right) \cdot\left(1-\frac{1}{T}\right)+\left(1-\alpha_{T}\right) \prod_{i=2}^{T}\left(1+\lambda_{i}\right)$

$\Gamma^{T} \quad=\frac{1}{1+r}+\left(\frac{1}{1+r}\right)^{2}+\ldots+\left(\frac{1}{1+r}\right)^{T}$

$C C_{T}=\frac{N_{T}}{D_{T}} \cdot \frac{1}{\Gamma^{T}}$ with $T, r, \gamma$, and $\lambda$ as defined above.

$C C_{T}^{\lambda} \quad=$ Same as $C C_{T}$ except that $\lambda_{t}=\lambda_{T}^{a}$ for all $t$.

$F B_{T} \quad=M B_{T}-C C_{T}$

$\hat{F B_{T}} \quad=$ Estimated Future-to-Book Value, defined in equation (23).

$\hat{C C_{T}} \quad=M B_{T}-\hat{F B} B_{T}$

EconCost $_{T}=\operatorname{Expenses}_{T}-\operatorname{dep}_{T}+\frac{1}{\Delta_{T}}\left(\operatorname{dep}_{T}+r \cdot O A_{T-1}\right)$

$\Delta_{T} \quad=\Gamma^{T} \cdot \frac{u_{0}+u_{1}\left(1+\lambda_{1}\right)+\cdots+u_{T-1} \prod_{i=1}^{T-1}\left(1+\lambda_{i}\right)+\alpha_{T} \cdot \prod_{i=1}^{T}\left(1+\lambda_{i}\right)}{1+\left(1+\lambda_{1}\right)+\cdots+\prod_{i=1}^{T-1}\left(1+\lambda_{i}\right)}$

$u_{t} \quad=\left(1-\alpha_{t}\right)\left[\frac{1}{T}+r \cdot\left(1-\frac{T-1-t}{T}\right)\right]$ for $0 \leq t \leq T-1$

$\mathcal{I}\{x\} \quad=\quad x$ if $x \geq 0$ and $\mathcal{I}\{x\}=0$ if $x \leq 0$

$\Gamma_{\lambda}^{5} \quad=$ Capitalization factor, given by $\sum_{i=1}^{5}\left(\frac{1+\lambda_{3}^{a}}{1+r}\right)^{i}$ 
Table 1: Sample selection criteria

\begin{tabular}{lc}
\hline \hline $\begin{array}{l}\text { Data available in Compustat } \\
\text { Market value not available }\end{array}$ & $\begin{array}{c}316,896 \\
(94,185)\end{array}$ \\
& $\frac{(582)}{222,711}$ \\
Book value of operating assets not available & 222,129 \\
Market value of net operating assets less than or equal to zero & $\frac{(13,831)}{208,298}$ \\
Missing data for calculation of conservatism correction, CC & $\frac{(38,410)}{169,888}$ \\
Ratio of Plant/Total assets less than 10\% & $\frac{(28,803)}{141,085}$ \\
Total assets less than $\$ 4$ million & $(3,069)$ \\
\hline
\end{tabular}


Table 2: Descriptive Statistics

Panel A: Fractiles of the distribution for key variables

\begin{tabular}{lrrrrrr}
\hline \hline Variable Label & $\mathrm{N}$ & Mean & Std Dev & 25 th Pctl & Median & 75 th Pctl \\
\hline$M B_{T}^{\text {un }}$ & 135623 & 2.490 & 2.895 & 1.000 & 1.625 & 2.763 \\
$M B_{T}$ & 135623 & 3.023 & 3.944 & 1.000 & 1.573 & 3.118 \\
Total Assets & 135623 & 1810.790 & 9868.830 & 34.360 & 129.874 & 637.542 \\
Capital intensity & 135623 & 0.394 & 0.219 & 0.215 & 0.340 & 0.544 \\
Advertising intensity & 135507 & 0.084 & 0.179 & 0.000 & 0.000 & 0.065 \\
$\mathrm{R} \&$ D intensity & 135507 & 0.147 & 0.243 & 0.000 & 0.000 & 0.231 \\
$T$ & 135623 & 14.791 & 7.078 & 10.000 & 14.000 & 18.000 \\
$\alpha_{T}^{a}$ & 135617 & 0.205 & 0.249 & 0.000 & 0.081 & 0.373 \\
$\lambda_{T}^{a}$ & 135621 & 0.225 & 0.582 & 0.031 & 0.120 & 0.263 \\
$\lambda_{3}^{a}$ & 135543 & 0.223 & 0.487 & -0.052 & 0.124 & 0.366 \\
$r$ & 135623 & 0.131 & 0.072 & 0.079 & 0.115 & 0.165 \\
$C C_{T}$ & 135623 & 1.865 & 1.346 & 1.166 & 1.367 & 1.978 \\
$C C_{T}^{\lambda}$ & 135431 & 1.897 & 2.918 & 1.154 & 1.334 & 1.915 \\
$F B_{T}$ & 135623 & 1.158 & 4.016 & -0.527 & 0.092 & 1.378 \\
$\tau$ & 135623 & 0.414 & 0.054 & 0.370 & 0.370 & 0.480 \\
$\hat{F} B_{T}$ & 135532 & 1.208 & 3.333 & 0.000 & 0.000 & 0.759 \\
$\hat{C} C_{T}$ & 135532 & 1.814 & 4.356 & 0.657 & 1.228 & 2.339 \\
\hline
\end{tabular}

Variables are defined in Appendix 1. The sample includes 135,623 observations from 19622007. 
U⿺辶寸

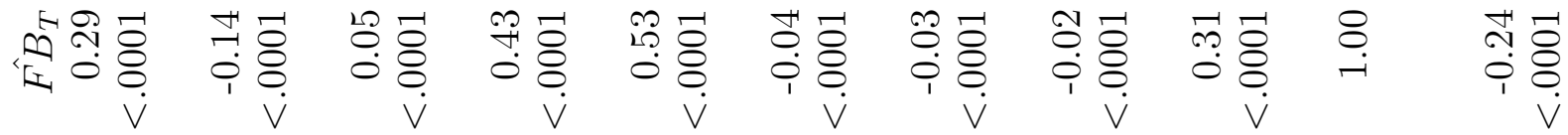

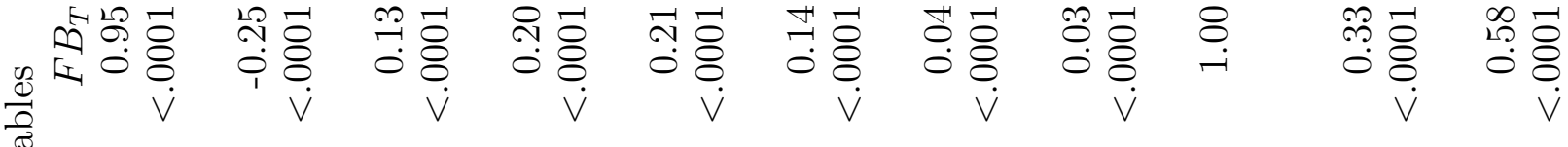

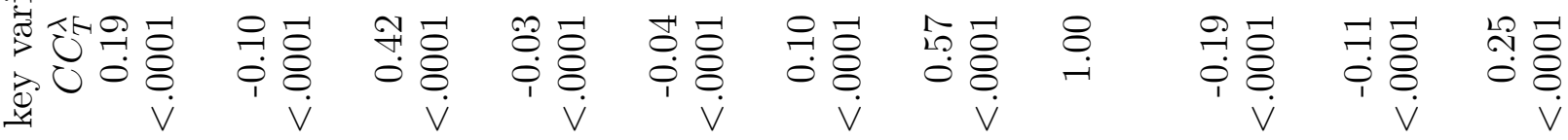

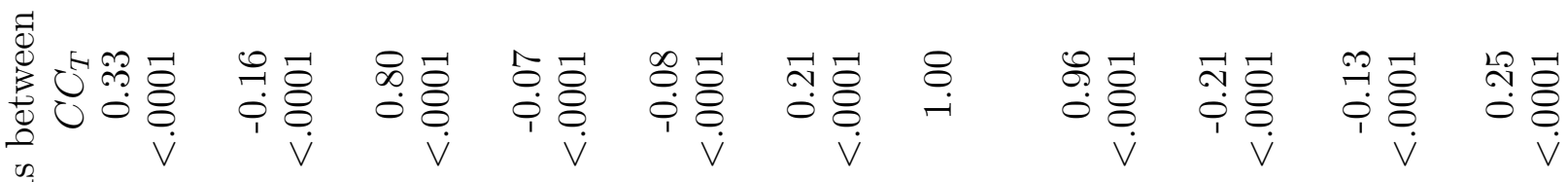

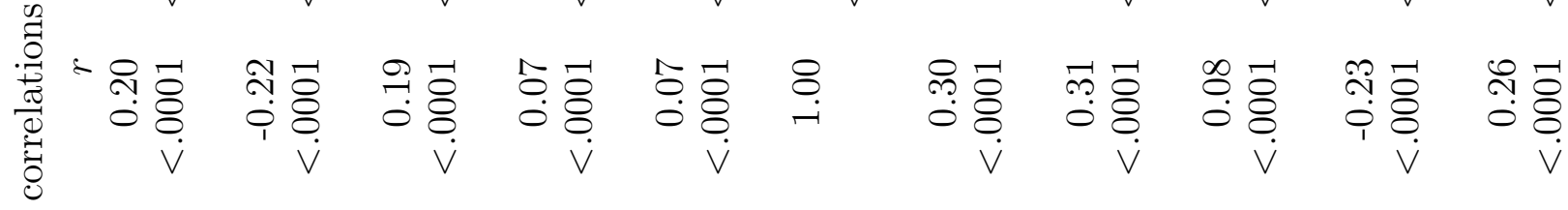
崖

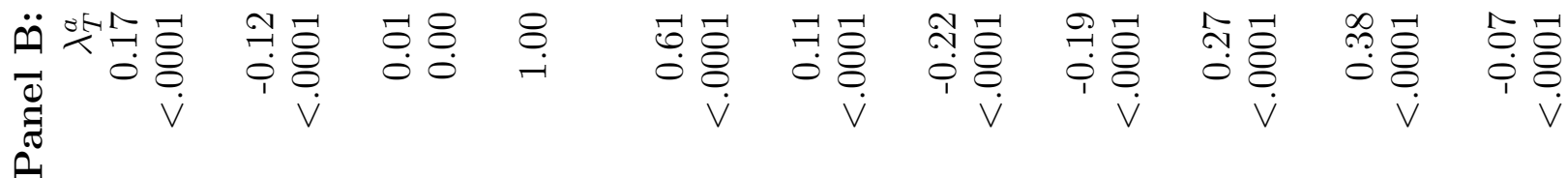

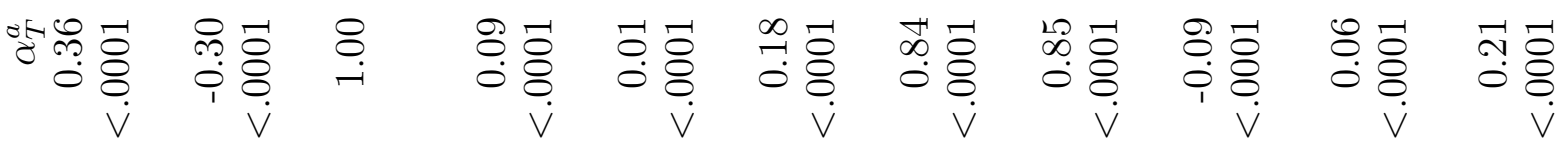

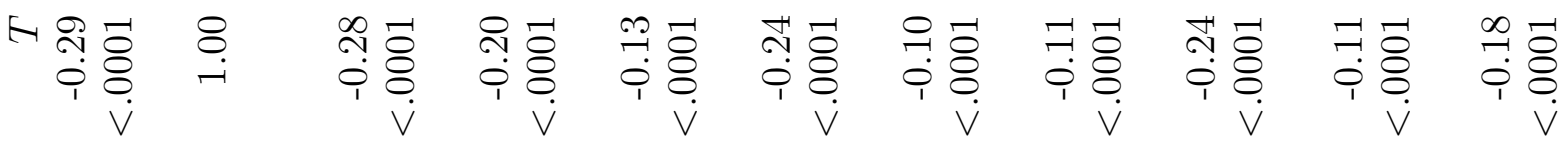

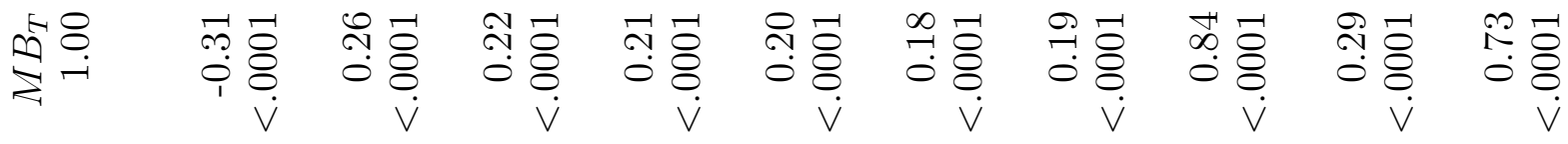

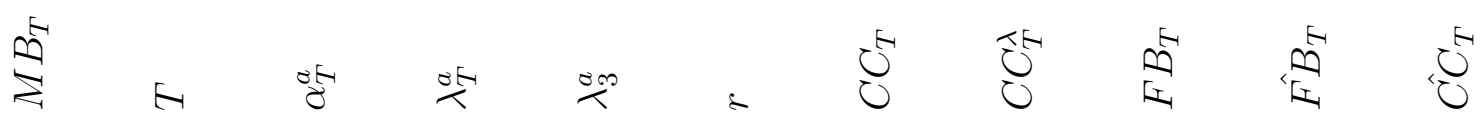


Table 3: Tests of hypothesized values for $C C_{T}$ and $F B_{T} \equiv M B_{T}-C C_{T}$

\begin{tabular}{|c|c|c|c|c|}
\hline & & Hypothesized & Standard & \\
\hline Variable & Mean & Value & Error of Mean & t-statistic \\
\hline$C C_{T}$ & 1.864 & 1 & 0.031 & $24.35^{*}$ \\
\hline$F B_{T}$ & 1.158 & 0 & 0.114 & $10.13^{*}$ \\
\hline
\end{tabular}

*The probability value of the test statistic is less than .0001 . 
Table 4: The relation between market-to-book, Tobin's $q$, and investment

Panel A: Estimation results for regression of $C A P X V_{T+1}^{\prime}$ on $M B_{T}, \hat{C C_{T}}$ and $q_{T}$.

$$
\begin{gathered}
C A P X V_{T+1}^{\prime}=\eta_{01}+\eta_{11} \cdot M B_{T}+\epsilon_{1} \\
C A P X V_{T+1}^{\prime}=\eta_{01}^{\prime}+\eta_{11}^{\prime} \cdot M B_{T}+\eta_{21}^{\prime} \cdot C C_{T}+\epsilon_{1}^{\prime}
\end{gathered}
$$

\begin{tabular}{|c|c|c|c|}
\hline & E1 & E1' & E2 \\
\hline \multirow[t]{2}{*}{ Intercept } & 0.148 & 0.180 & 0.134 \\
\hline & $(29.77)$ & $(37.13)$ & $(22.86)$ \\
\hline \multirow[t]{2}{*}{$M B_{T}$} & 0.014 & 0.016 & \\
\hline & $(29.71)$ & $(41.61)$ & \\
\hline \multirow[t]{2}{*}{$C C_{T}$} & & -0.021 & \\
\hline & & $(-13.71)$ & \\
\hline \multirow[t]{2}{*}{$q_{T}$} & & & 0.034 \\
\hline & & & $(32.12)$ \\
\hline Adjusted $R^{2}$ & 0.134 & 0.160 & 0.180 \\
\hline$n$ & 105,407 & 105,407 & 105,407 \\
\hline
\end{tabular}

\begin{tabular}{|c|c|c|c|}
\hline & Model 1 & Model 2 & \\
\hline Equation & E1 & E2 & \\
\hline Expanding Variable & $M B_{T}$ & $q_{T}$ & \\
\hline Number of Observations & 105,407 & 105,407 & \\
\hline Number of Parameters & 2 & 2 & \\
\hline Log Likelihood & -2834186.4 & -2613350.5 & \\
\hline Vuong z-Statistic & & & -34.9825 \\
\hline $\operatorname{Pr}>|z|$ & & & $<.0001$ \\
\hline Preferred Model & & & $\mathrm{E} 2$ \\
\hline
\end{tabular}

Panel B: Results of the Vuong Test

The Vuong Statistic tests the null hypothesis that the models are equally close to the true model against the alternate that one of the models is closer to the true model. 
Table 5: The relation between market-to-book, conservatism correction, and estimated future-to-book

Estimation results from regression of market-to-book on the conservatism correction factor and estimated future-to-book ratio. Coefficients are shown with t-statistics in parentheses.

$$
M B_{T}=\eta_{03}+\eta_{13} \cdot C C_{T}+\eta_{23} \cdot \hat{F B} B_{T}+\epsilon_{3} .
$$

\begin{tabular}{lrrr}
\hline \hline Variables & $(1)$ & $(2)$ & $(3)$ \\
\cline { 2 - 4 } Intercept & 0.984 & 1.963 & 0.660 \\
& $(15.11)$ & $(29.39)$ & $(10.57)$ \\
$C C_{T}$ & 0.716 & & 0.759 \\
& $(23.45)$ & & $(26.17)$ \\
$\hat{F} B_{T}$ & & 0.274 & 0.294 \\
& & $(22.12)$ & $(23.84)$ \\
Adjusted $R^{2}$ & 0.122 & 0.129 & 0.244 \\
$n$ & 127,866 & 127,604 & 127,375 \\
\hline
\end{tabular}


Table 6: The relation between $\alpha$ and $M B_{T}$

Panel A: Mean values of selected variables ranked by half-deciles of $\alpha_{T}^{a}$

\begin{tabular}{lrrrrrr} 
Rank & $n$ & $\alpha_{T}^{a}$ & $M B_{T}$ & $C C_{T}$ & $F B_{T}$ & $\hat{F} B_{T}$ \\
\hline 3 & 46879 & 0.000 & 2.242 & 1.228 & 1.023 & 1.014 \\
6 & 587 & 0.001 & 1.876 & 1.347 & 0.532 & 0.526 \\
7 & 6781 & 0.008 & 1.798 & 1.241 & 0.562 & 0.547 \\
8 & 6781 & 0.030 & 1.886 & 1.257 & 0.633 & 0.610 \\
9 & 6780 & 0.062 & 2.108 & 1.288 & 0.825 & 0.749 \\
10 & 6781 & 0.104 & 2.260 & 1.344 & 0.925 & 0.804 \\
11 & 6781 & 0.155 & 2.407 & 1.423 & 0.996 & 0.800 \\
12 & 6781 & 0.210 & 2.508 & 1.530 & 0.992 & 0.754 \\
13 & 6781 & 0.273 & 2.773 & 1.663 & 1.129 & 0.791 \\
14 & 6781 & 0.338 & 2.920 & 1.823 & 1.119 & 0.729 \\
15 & 6781 & 0.408 & 3.376 & 2.041 & 1.370 & 0.803 \\
16 & 6781 & 0.483 & 3.884 & 2.343 & 1.604 & 0.789 \\
17 & 6781 & 0.566 & 4.898 & 2.781 & 2.245 & 0.915 \\
18 & 6781 & 0.666 & 5.978 & 3.605 & 2.595 & 0.801 \\
19 & 6780 & 0.798 & 7.993 & 6.348 & 2.494 & 0.349
\end{tabular}

Panel B:

$$
\ln \left(M B_{T}\right)=\eta_{04}+\eta_{14} \cdot \ln \left(1-\alpha_{T}^{a}\right)+\epsilon_{4}
$$

\begin{tabular}{lr} 
Variables & Coefficients \\
\hline Intercept & 0.333 \\
& $(9.86)$ \\
$\ln \left(1-\alpha_{T}^{a}\right)$ & -0.846 \\
& $(-29.94)$ \\
Adjusted $R^{2}$ & 0.198 \\
$n$ & 127,969
\end{tabular}


Table 7: The relation between market-to-book and growth

Panel A: Market-to-book partitioned by $\lambda$

\begin{tabular}{lrrrrrrr}
\hline \hline Rank & $n$ & $\lambda_{T}^{a}$ & $M B_{T}$ & $C C_{T}$ & $F B_{T}$ & $\hat{F B_{T}}$ & $\hat{C C_{T}}$ \\
\hline 0 & 6781 & -0.442 & 2.71 & 2.176 & 0.597 & 0.200 & 2.511 \\
1 & 6781 & -0.152 & 2.414 & 1.942 & 0.522 & 0.295 & 2.116 \\
2 & 6781 & -0.060 & 2.394 & 1.930 & 0.504 & 0.313 & 2.080 \\
3 & 6781 & -0.012 & 2.386 & 1.900 & 0.525 & 0.341 & 2.045 \\
4 & 6781 & 0.019 & 2.238 & 1.854 & 0.423 & 0.336 & 1.902 \\
5 & 6781 & 0.042 & 2.287 & 1.856 & 0.460 & 0.396 & 1.892 \\
6 & 6781 & 0.061 & 2.249 & 1.836 & 0.445 & 0.409 & 1.840 \\
7 & 6781 & 0.078 & 2.275 & 1.845 & 0.466 & 0.447 & 1.827 \\
8 & 6781 & 0.094 & 2.322 & 1.823 & 0.533 & 0.470 & 1.851 \\
9 & 6781 & 0.111 & 2.446 & 1.839 & 0.643 & 0.603 & 1.842 \\
10 & 6782 & 0.130 & 2.484 & 1.832 & 0.686 & 0.636 & 1.848 \\
11 & 6781 & 0.151 & 2.702 & 1.838 & 0.913 & 0.728 & 1.973 \\
12 & 6781 & 0.175 & 2.876 & 1.883 & 1.047 & 0.875 & 2.000 \\
13 & 6781 & 0.204 & 3.064 & 1.897 & 1.239 & 0.995 & 2.068 \\
14 & 6781 & 0.241 & 3.279 & 1.898 & 1.463 & 1.157 & 2.123 \\
15 & 6781 & 0.290 & 3.608 & 1.884 & 1.838 & 1.371 & 2.238 \\
16 & 6781 & 0.359 & 3.902 & 1.877 & 2.151 & 1.605 & 2.297 \\
17 & 6781 & 0.472 & 4.279 & 1.844 & 2.578 & 2.000 & 2.278 \\
18 & 6781 & 0.702 & 4.932 & 1.805 & 3.319 & 3.263 & 1.670 \\
19 & 6781 & 2.034 & 5.606 & 1.531 & 4.258 & 7.718 & -2.113 \\
\hline
\end{tabular}




\section{Panel B:}

$$
\hat{C C_{T}}=\eta_{05}+\eta_{15} \cdot \alpha_{T}^{a}+\eta_{25} \cdot \lambda_{T}^{a}+\eta_{35} \cdot r_{T}+\epsilon_{5}
$$

Estimation results for regression of the estimated conservatism correction factor, $\hat{C C_{T}}$, on average growth

\begin{tabular}{lcccccc} 
& 1 & 2 & 3 & 4 & 5 & 6 \\
\hline \multirow{3}{*}{ Intercept } & & $\alpha_{T}^{a}>0.08$ & $\alpha_{T}^{a} \leq 0.08$ & & $\alpha_{T}^{a}>0.08$ & $\alpha_{T}^{a} \leq 0.08$ \\
& 0.455 & -0.551 & 0.816 & 35.370 & 19.140 & 41.130 \\
$\alpha_{T}^{a}$ & $(2.99)$ & $(-2.64)$ & $(8.12)$ & $(17.12)$ & $(7.01)$ & $(21.58)$ \\
& 2.196 & 4.011 & -2.290 & 0.163 & 0.362 & 0.020 \\
$\lambda_{T}^{a}$ & $(13.33)$ & $(20.52)$ & $(-2.23)$ & $(6.01)$ & $(9.72)$ & $(0.73)$ \\
& -1.082 & -1.530 & -0.814 & -0.081 & -0.095 & -0.087 \\
$r_{T}$ & $(-10.44)$ & $(-7.44)$ & $(-12.69)$ & $(-4.70)$ & $(-4.28)$ & $(-5.01)$ \\
& 6.663 & 8.740 & 4.727 & 0.208 & 0.237 & 0.172 \\
Adjusted $R^{2}$ & $(6.19)$ & $(6.58)$ & $(6.74)$ & $(18.06)$ & $(16.34)$ & $(14.47)$ \\
$n$ & 0.155 & 0.192 & 0.081 & 0.084 & 0.094 & 0.040 \\
& 125,456 & 62,317 & 63,281 & 135,531 & 67,933 & 67,598
\end{tabular}




\section{Panel C:}

$$
\hat{C C_{T}}=\eta_{05}^{\prime}+\eta_{15}^{\prime} \cdot \alpha_{T}^{a}+\eta_{25}^{\prime} \cdot \lambda_{T}^{a+}+\eta_{35}^{\prime} \cdot \lambda_{T}^{a-}+\eta_{45}^{\prime} \cdot r_{T}+\epsilon_{5}^{\prime}
$$

Estimation results for regression of the estimated conservatism correction factor, $\hat{C C_{T}}$, on average growth, partitioned into positive and negative average growth: $\lambda_{T}^{a+}$ and $\lambda_{T}^{a-}$

\begin{tabular}{lcccccc} 
& 1 & 2 & 3 & 4 & 5 & 6 \\
\hline \multirow{2}{*}{ Intercept } & & $\alpha_{T}^{a}>0.08$ & $\alpha_{T}^{a} \leq 0.08$ & & $\alpha_{T}^{a}>0.08$ & $\alpha_{T}^{a} \leq 0.08$ \\
& $(2.91)$ & $(-2.58)$ & $(8.31)$ & $(19.74)$ & $(6.78)$ & $(23.89)$ \\
$\alpha_{T}^{a}$ & 2.177 & 3.950 & -2.520 & 0.156 & 0.351 & 0.015 \\
& $(13.41)$ & $(20.00)$ & $(-2.45)$ & $(5.61)$ & $(9.20)$ & $(0.56)$ \\
$\lambda_{T}^{a-}$ & -0.743 & -1.441 & -0.217 & -9.371 & -16.950 & -5.812 \\
& $(-5.08)$ & $(-4.49)$ & $(-2.50)$ & $(-4.95)$ & $(-4.17)$ & $(-3.29)$ \\
$\lambda_{T}^{a+}$ & -0.887 & -0.993 & -0.863 & -5.614 & -6.400 & -5.4414 \\
& $(-15.03)$ & $(-8.89)$ & $(-17.96)$ & $(-8.45)$ & $(-6.47)$ & $(-8.51)$ \\
$r_{T}$ & 6.562 & 8.519 & 4.842 & 0.207 & 0.236 & 0.172 \\
& $(6.12)$ & $(6.41)$ & $(6.82)$ & $(18.09)$ & $(16.62)$ & $(14.57)$ \\
Adjusted $R^{2}$ & 0.168 & 0.189 & 0.129 & 0.091 & 0.094 & 0.050 \\
$n$ & 125,645 & 62,233 & 63,296 & 135,531 & 67,923 & 67,598
\end{tabular}




\section{Appendix 2 - Proofs}

Proof of Proposition 1: We can set $\alpha$ to 0 without loss of generality for this proof. From (8), $C C_{T}$ equals (after dividing through by the common term $I_{0} \cdot\left(1+\lambda_{1}\right)$ ):

$$
C C_{T}=\frac{B V_{T}\left(\mathbf{I}_{T}, \mathbf{d}^{*}\right)}{B V_{T}\left(\mathbf{I}_{T}, \mathbf{d}^{o}\right)}=\frac{b v_{T-1}^{*}+b v_{T-2}^{*} \cdot\left(1+\lambda_{2}\right)+\ldots+b v_{0}^{*} \cdot \prod_{i=2}^{T}\left(1+\lambda_{i}\right)}{b v_{T-1}^{o}+b v_{T-2}^{o} \cdot\left(1+\lambda_{2}\right)+\ldots+b v_{0}^{o} \cdot \prod_{i=2}^{T}\left(1+\lambda_{i}\right)}
$$

This ratio is decreasing in $\lambda_{t}$ if and only if the sequence $\frac{b v_{t}^{*}}{b v_{t}^{o}}$ is an increasing function of $t .^{31}$ Given the replacement cost accounting rule, $\mathbf{d}^{*}$, we know from (6) and (11) that $z_{t}^{*}=x_{t}=0$ for $1 \leq t \leq L-1$ and $z_{t}^{*}=c \cdot x_{t}$, for $L \leq t \leq T$. It follows that for all $t, z_{t}^{*}=c \cdot x_{t}$. We recall the following identity linking book values to future "residual income charges."

$$
b v_{t}(\mathbf{d})=\sum_{i=t+1}^{T} z_{i}(\mathbf{d}) \cdot \gamma^{i-t}
$$

Denoting $b v_{t}^{o} \equiv b v_{t}\left(\mathbf{d}^{\mathbf{o}}\right)$, we have:

$$
\frac{b v_{t}^{*}}{b v_{t}^{o}}=\frac{\sum_{i=t+1}^{T} z_{i}\left(\mathbf{d}^{*}\right) \cdot \gamma^{i-t}}{\sum_{i=t+1}^{T} z_{i}\left(\mathbf{d}^{\mathbf{o}}\right) \cdot \gamma^{i-t}}=\frac{c \cdot \sum_{i=t+1}^{T} x_{i} \cdot \gamma^{i}}{\sum_{i=t+1}^{T} z_{i}\left(\mathbf{d}^{\mathbf{o}}\right) \cdot \gamma^{i}} .
$$

Analogously, we have:

$$
\frac{b v_{t-1}^{*}}{b v_{t-1}^{o}}=\frac{c \cdot \sum_{i=t}^{T} x_{i} \cdot \gamma^{i}}{\sum_{i=t}^{T} z_{i}\left(\mathbf{d}^{\mathbf{o}}\right) \cdot \gamma^{i}}=\frac{c \cdot\left[x_{t} \cdot \gamma^{t}+\sum_{i=t+1}^{T} x_{i} \cdot \gamma^{i}\right]}{z_{t}\left(\mathbf{d}^{\mathbf{o}}\right) \cdot \gamma^{t}+\sum_{i=t+1}^{T} z_{i}\left(\mathbf{d}^{\mathbf{o}}\right) \cdot \gamma^{i}} .
$$

To establish that $(27) \geq(28)$, we note that, for $1 \leq t \leq L-1$, the inequality follows immediately since $x_{t}=0$ and $z_{t}\left(\mathbf{d}^{\mathbf{o}}\right) \geq 0$ (see Definition 2). For $t \geq L$, the result holds if and only if

$$
\frac{z_{t}\left(\mathbf{d}^{\mathbf{o}}\right)}{x_{t}} \geq \frac{\sum_{i=t+1}^{T} z_{i}\left(\mathbf{d}^{\mathbf{o}}\right) \cdot \gamma^{i}}{\sum_{i=t+1}^{T} x_{i} \cdot \gamma^{i}}
$$

\footnotetext{
${ }^{31} \mathrm{~A}$ proof of this assertion can be found in Claim 2 in the proof of Proposition 3 in Rajan and Reichelstein (2009).
} 
We demonstrate that (29) is true by a process of induction. For $t=T-1$, (29) requires:

$$
\frac{z_{T-1}\left(\mathbf{d}^{\mathbf{o}}\right)}{x_{T-1}} \geq \frac{z_{T}\left(\mathbf{d}^{\mathbf{o}}\right)}{x_{T}}
$$

which is true as $\frac{z_{t}\left(\mathbf{d}^{\mathbf{0}}\right)}{x_{t}}$ decreases in $t$. Now suppose that (29) holds for $\mathrm{t}=\mathrm{k}$. Then, for $\mathrm{t}=\mathrm{k}-1$,

$$
\frac{z_{k-1}\left(\mathbf{d}^{\mathbf{o}}\right)}{x_{k-1}} \geq \frac{z_{k}\left(\mathbf{d}^{\mathbf{o}}\right)}{x_{k}}=\frac{z_{k}\left(\mathbf{d}^{\mathbf{o}}\right) \cdot \gamma^{k}}{x_{k} \cdot \gamma^{k}} \geq \frac{z_{k}\left(\mathbf{d}^{\mathbf{o}}\right) \cdot \gamma^{k}+\sum_{i=k+1}^{T} z_{i}\left(\mathbf{d}^{\mathbf{o}}\right) \cdot \gamma^{i}}{x_{k} \cdot \gamma^{k}+\sum_{i=k+1}^{T} x_{i} \cdot \gamma^{i}}=\frac{\sum_{i=k}^{T} z_{i}\left(\mathbf{d}^{\mathbf{o}}\right) \cdot \gamma^{i}}{\sum_{i=k}^{T} x_{i} \cdot \gamma^{i}},
$$

where the second inequality arises from the induction hypothesis. We have thus shown that (29) holds. To conclude, note that we have stated the proof in terms of weak inequalities. However, if either $z_{t}\left(\mathbf{d}^{\mathbf{o}}\right)>0$ for some $t \leq L-1$ or $\frac{z_{t}\left(\mathbf{d}^{\mathbf{o}}\right)}{x_{t}}$ strictly decreases in $t$ for $t \geq L$, it follows that $\frac{b v_{t}^{*}}{b v_{t}^{o}}$ strictly increases for some subset of values of $t$ and therefore that $C C_{T}$ is monotone decreasing in each $\lambda_{t}$.

Proof of Proposition 2: Consider $C C_{T}$ as represented in equation (26). The denominator, $B V_{T}$, is determined by the depreciation scheme under consideration and is independent of the cost of capital, $r$. So it is sufficient to show that the numerator, $B V_{T}^{*}$, increases in $r$, or, equivalently, that it decreases in $\gamma$. We use the following formulation of $B V_{T}\left(\mathbf{I}_{T}, \mathbf{d}^{*}\right)$ :

$$
B V_{T}\left(\mathbf{I}_{T}, \mathbf{d}^{*}\right)=b v_{T-1}^{*} \cdot I_{1}+b v_{T-2}^{*} \cdot I_{2}+\ldots+b v_{0}^{*} \cdot I_{T} .
$$

As in the proof of Proposition 1, we set $b v_{t}^{*}=c \cdot \sum_{i=t+1}^{T} x_{i} \cdot \gamma^{i-t} . B V_{T}\left(\mathbf{I}_{T}, \mathbf{d}^{*}\right)$ therefore equals:

$$
c \cdot\left[I_{1} \cdot \sum_{i=T}^{T} x_{i} \cdot \gamma^{i-(T-1)}+I_{2} \cdot \sum_{i=T-1}^{T} x_{i} \cdot \gamma^{i-(T-2)}+\ldots+I_{T} \cdot \sum_{i=1}^{T} x_{i} \cdot \gamma^{i}\right] .
$$

As $c=\frac{1}{\sum_{i=L}^{T} x_{i} \cdot \gamma^{i}}$, we need to show that the following expression decreases in $\gamma$ :

$$
\frac{I_{1} \cdot x_{T} \cdot \gamma+I_{2} \cdot \sum_{i=T-1}^{T} x_{i} \cdot \gamma^{i-(T-2)}+\ldots+I_{T} \cdot \sum_{i=1}^{T} x_{i} \cdot \gamma^{i}}{\sum_{i=L}^{T} x_{i} \cdot \gamma^{i}} .
$$

We do so one term at a time. Ignoring the positive constant $I_{t}$, an arbitrary term in (30) is of the form:

$$
\frac{\sum_{i=k}^{T} x_{i} \cdot \gamma^{i-k+1}}{\sum_{i=L}^{T} x_{i} \cdot \gamma^{i}}, \quad k \in\{1,2, \ldots, T\}
$$


Consider $k \leq L$. As $x_{1}=\ldots=x_{L-1}=0$, (31) is equivalent to:

$$
\frac{\sum_{i=L}^{T} x_{i} \cdot \gamma^{i-k+1}}{\sum_{i=L}^{T} x_{i} \cdot \gamma^{i}}=\gamma^{-(k-1)},
$$

which is decreasing in $\gamma$ as $k \geq 1$.

For $k>L,(31)$ decreases in $\gamma$ if and only if

$$
\begin{gathered}
\left(\sum_{i=L}^{T} x_{i} \cdot \gamma^{i}\right) \cdot\left[\sum_{i=k}^{T} x_{i} \cdot(i-k+1) \cdot \gamma^{i-k}\right] \leq\left[\sum_{i=k}^{T} x_{i} \cdot \gamma^{i-k+1}\right] \cdot\left(\sum_{i=L}^{T} x_{i} \cdot i \cdot \gamma^{i-1}\right) \text {, or } \\
\frac{\sum_{i=L}^{T} x_{i} \cdot \gamma^{i-1}}{\sum_{i=L}^{T} x_{i} \cdot i \cdot \gamma^{i-1}} \leq \frac{\sum_{i=k}^{T} x_{i} \cdot \gamma^{i-k}}{\sum_{i=k}^{T} x_{i} \cdot(i-k+1) \cdot \gamma^{i-k}}
\end{gathered}
$$

With regard to the left-hand side of (33), note that:

$$
\frac{\sum_{i=L}^{T} x_{i} \cdot \gamma^{i-1}}{\sum_{i=L}^{T} x_{i} \cdot i \cdot \gamma^{i-1}}<\frac{\sum_{i=L}^{L+T-k} x_{i} \cdot \gamma^{i-1}}{\sum_{i=L}^{L+T-k} x_{i} \cdot i \cdot \gamma^{i-1}} .
$$

since each additional term in the former has a numerator-to-denominator ratio of less than $1 /(L+T-k)$. So it is sufficient to demonstrate that

$$
\begin{gathered}
\frac{\sum_{i=L}^{L+T-k} x_{i} \cdot \gamma^{i-1}}{\sum_{i=L}^{L+T-k} x_{i} \cdot i \cdot \gamma^{i-1}} \leq \frac{\sum_{i=k}^{T} x_{i} \cdot \gamma^{i-k}}{\sum_{i=k}^{T} x_{i} \cdot(i-k+1) \cdot \gamma^{i-k}} \\
\Leftrightarrow \frac{\sum_{i=L}^{L+T-k} x_{i} \cdot \gamma^{i-L}}{\sum_{i=k}^{T} x_{i} \cdot \gamma^{i-k}} \leq \frac{\sum_{i=L}^{L+T-k} x_{i} \cdot i \cdot \gamma^{i-L}}{\sum_{i=k}^{T} x_{i} \cdot(i-k+1) \cdot \gamma^{i-k}} .
\end{gathered}
$$

Since $x_{i} / x_{i+1}$ increases in $i$, we know that $\frac{x_{L}}{x_{k}} \leq \frac{x_{L+1}}{x_{k+1}} \cdots \leq \frac{x_{L+T-k}}{x_{T}}$. The left-hand side of (34) places equal weight on these ratios, which implies that

$$
\frac{\sum_{i=L}^{L+T-k} x_{i} \cdot \gamma^{i-L}}{\sum_{i=k}^{T} x_{i} \cdot \gamma^{i-k}}<\frac{\sum_{i=L}^{L+T-k} x_{i} \cdot(i-L+1) \cdot \gamma^{i-L}}{\sum_{i=k}^{T} x_{i} \cdot(i-k+1) \cdot \gamma^{i-k}},
$$


since the expression on the right-hand side of (35) places increasingly higher weights on the higher ratios. Finally, $L \geq 1$ implies that the right-hand side of (34) exceeds the right-hand side of (35). Hence, the inequality in (34) holds, and we have shown that $B V_{T}\left(\mathbf{I}_{T}, \mathbf{d}^{*}\right.$ ) (and hence $C C_{T}$ ) increases in $r$.

Proof of Proposition 3: For $L=1$, we have $x_{t}=1-\beta \cdot(t-1)$. The capital charges in (16) simplify to:

$$
z_{t}=\frac{1-\alpha}{T} \cdot[1+r \cdot(T-t+1)]
$$

Using these expressions, as well as the definition of $c$, we can rewrite $C C_{T}$ in (15) as:

$$
C C_{T}=\frac{T}{\sum_{i=1}^{T}[1-\beta \cdot(i-1)] \cdot \gamma^{i}} \cdot \frac{\sum_{i=1}^{T}[1-\beta \cdot(i-1)] \cdot\left(\gamma^{i}-\mu^{i}\right)}{\sum_{i=1}^{T}[1+r \cdot(T-i+1)] \cdot\left(\gamma^{i}-\mu^{i}\right)} \cdot \frac{1}{1-\alpha} .
$$

Expanding this expression, it can then be shown that the limit values of the $C C_{T}$ function are as follows:

$$
\begin{aligned}
& \lim _{\lambda \rightarrow-1} C C_{T}(\cdot)=\left(\frac{1}{1-\alpha}\right) \cdot \frac{T \cdot r^{2} \cdot(1+r)^{T-1} \cdot[1-\beta \cdot(T-1)]}{(r-\beta) \cdot\left[(1+r)^{T}-1\right]+\beta \cdot r \cdot T} \\
& \lim _{\lambda \rightarrow 0} C C_{T}(\cdot)=\left(\frac{1}{1-\alpha}\right) \cdot\left[\frac{T \cdot[2+\beta \cdot(1-T)] \cdot r^{2} \cdot(1+r)^{T}}{(r-\beta) \cdot\left[(1+r)^{T}-1\right]+\beta \cdot r \cdot T}-2\right] \cdot \frac{1}{r \cdot[T+1]} \\
& \lim _{\lambda \rightarrow \infty} C C_{T}(\cdot)=\frac{1}{1-\alpha} .
\end{aligned}
$$

The limit results for the $\beta=0$ case follow directly from these expressions.

We next prove the claim regarding the bounds on the ratios of the $C C_{T}$ variables. Note that the term $1 /(1-\alpha)$ enters in a multiplicative fashion in each of the $C C_{T}$ expressions in (37) and, as such, can be ignored. Also, when $T=2$, direct computations on (37) reveal that the ratio in question always equals $\frac{2}{3}$. We therefore restrict attention to values of $T>2$. We first show the upper bound result that

$$
\frac{C C_{T}(\lambda=-1)-C C_{T}(\lambda=0)}{C C_{T}(\lambda=-1)-C C_{T}(\lambda=\infty)} \leq \frac{T}{T+1} .
$$

To do so, we will demonstrate the equivalent result that

$$
\frac{C C_{T}(\lambda=0)-C C_{T}(\lambda=\infty)}{C C_{T}(\lambda=-1)-C C_{T}(\lambda=\infty)} \geq \frac{1}{T+1} .
$$


Using the limits in (37), (38) reduces to the following inequality:

$$
\begin{gathered}
(T+1) \cdot\left[\frac{1}{r(1+T)} \cdot \frac{\operatorname{Tr}^{2}(1+r)^{T}(2+\beta-\beta T)}{\beta r T+(r-\beta)\left[(1+r)^{T}-1\right]}-\frac{2}{r(1+T)}-1\right] \\
\geq \frac{\operatorname{Tr}^{2}(1+r)^{T-1}[1+\beta-\beta T]}{\beta r T+(r-\beta)\left[(1+r)^{T}-1\right]}-1 . \\
\Leftrightarrow \quad(T+1) \operatorname{Tr}^{2}(1+r)^{T}(2+\beta-\beta T)-(T+1)[2+r(1+T)] \cdot\left[\beta r T+(r-\beta) \cdot\left[(1+r)^{T}-1\right]\right] \\
\quad \geq \operatorname{Tr}^{2}(1+r)^{T-1}[1+\beta-\beta T] r(1+T)-r(1+T)\left[\beta r T+(r-\beta)\left[(1+r)^{T}-1\right]\right] \\
\Leftrightarrow \operatorname{Tr}^{2}(1+r)^{T-1}(1+\beta-\beta T)+\operatorname{Tr}^{2}(1+r)^{T}-\left[\beta r T+(r-\beta)\left[(1+r)^{T}-1\right]\right](2+r T) \geq 0 \\
\Leftrightarrow \operatorname{Tr}^{2}(1+r)^{T-1}(2+\beta-\beta T+r)-(2+r T)\left[\beta r T+(r-\beta)\left[(1+r)^{T}-1\right]\right] \geq 0 .
\end{gathered}
$$

But (39) is a linear function of $\beta$. At $\beta=\frac{r}{1+r T}$, (39) equals

$$
\frac{\operatorname{Tr}^{2}(1+r)^{T}(2+r T)}{(1+r T)}-\frac{\operatorname{Tr}^{2}(1+r)^{T}(2+r T)}{(1+r T)}=0
$$

At $\beta=0$, the expression in (39) reduces to (after dividing through by $r$ ):

$$
T \cdot r \cdot(1+r)^{T-1}(2+r)-(2+r T)\left[-1+(1+r)^{T}\right] \geq 0 .
$$

Letting $s=(1+r) \geq 1$, this inequality holds if and only if

$$
T \cdot(s-1) \cdot s^{T-1} \cdot(s+1)-2\left(s^{T}-1\right)-\left(s^{T}-1\right) \cdot T \cdot(s-1) \geq 0,
$$

or

$$
T \cdot(s-1)\left(s^{T-1}+1\right)-2\left(s^{T}-1\right) \geq 0 .
$$

But this function and its first derivative equal 0 at $s=1$, while the second derivative is

$$
(s-1) \cdot T \cdot(T-1) s^{T-3} \cdot(T-2) \geq 0,
$$

for all $s \geq 1$. So the function is convex and positive everywhere. Thus (39) $\geq 0$ for all $\beta \in\left[0, \frac{r}{1+r T}\right]$. We have therefore shown that (38) holds.

We next demonstrate the lower bound inequality:

$$
\frac{C C_{T}(\lambda=-1)-C C_{T}(\lambda=0)}{C C_{T}(\lambda=-1)-C C_{T}(\lambda=\infty)} \geq \frac{2}{3}
$$

Expanding these expressions using (37), we seek to show that

$$
\frac{\operatorname{Tr}^{2}(1+r)^{T-1}(1+\beta-\beta T)}{(r-\beta)\left[(1+r)^{T}-1\right]+\beta r T}-\frac{6 \operatorname{Tr}^{2}(1+r)^{T}(2+\beta-\beta T)}{2 r(1+T)\left[\beta r T+(r-\beta)\left[(1+r)^{T}-1\right]\right]}+\frac{6}{r(1+T)}+2 \geq 0,
$$




$$
\begin{gathered}
\Leftrightarrow \operatorname{Tr}^{3}(1+r)^{T-1}(1+T)(1+\beta-\beta T)-3 \operatorname{Tr}^{2}(1+r)^{T}(2+\beta-\beta T)+6\left[\beta r T+(r-\beta)\left[(1+r)^{T}-1\right]\right] \\
+2 r(1+T)\left[\beta r T+(r-\beta)\left[(1+r)^{T}-1\right]\right] \geq 0, \\
\Leftrightarrow \operatorname{Tr}^{2}(1+r)^{T-1}(1+\beta-\beta T)[r+r T-3(1+r)]
\end{gathered}
$$

Again, this is a linear function of $\beta$, so it suffices to show that (40) holds at its end points. At $\beta=\frac{r}{1+r T}$, the expression reduces to

$$
\begin{aligned}
& \operatorname{Tr}^{2}(1+r)^{T-1} \frac{(1+r)}{(1+r T)}[r(1+T)-3(1+r)]-3 \operatorname{Tr}^{2}(1+r)^{T}+2[3+r+r T] \cdot \frac{r^{2}(1+r)^{T} T}{(1+r T)} \\
= & \frac{\operatorname{Tr}^{2}(1+r)^{T}}{(1+r T)}[r+r T-3-3 r+6+2 r+2 r T]-3 \operatorname{Tr}^{2}(1+r)^{T} \\
= & \frac{\operatorname{Tr}^{2}(1+r)^{T}}{(1+r T)}[3(1+r T)]-3 \operatorname{Tr}^{2}(1+r)^{T}=0 .
\end{aligned}
$$

At $\beta=0$, we need to show that

$$
\begin{aligned}
& \operatorname{Tr}^{3}(1+r)^{T-1}(1+T)-6 \operatorname{Tr}^{2}(1+r)^{T}+6 r\left((1+r)^{T}-1\right)+2 r^{2}(1+T)\left((1+r)^{T}-1\right) \geq 0 \\
& \Leftrightarrow T(1+T) s^{T-1}\left(s^{2}-2 s+1\right)-6 T(s-1) s^{T}+6\left(s^{T}-1\right)+2(1+T)(s-1)\left(s^{T}-1\right) \geq 0 \\
& \Leftrightarrow T(1+T) s^{T+1}-2 T(1+T) s^{T}+T(1+T) s^{T-1}-6 T s^{T+1}+6 T s^{T}+6 s^{T}-6 \\
& \quad+2(1+T) s^{T+1}-2(1+T) s^{T}-2 s(1+T)+2(1+T) \geq 0
\end{aligned}
$$

Again, this equals 0 at $s=1$. In addition, its derivative is

$$
\begin{gathered}
(T-2)(T-1)(T+1) s^{T}-2(T-2)(T+1) T s^{T-1}+T(1+T)(T-1) s^{T-2}-2(1+T) \\
\propto(T-2)(T-1) s^{T}-2(T-2) T s^{T-1}+T(T-1) s^{T-2}-2 .
\end{gathered}
$$

This equals 0 at $s=1$. Its derivative in turn is

$$
\begin{aligned}
& T(T-2)(T-1) s^{T-1}-2 T(T-1)(T-2) s^{T-2}+T(T-1)(T-2) s^{T-3} \\
= & T(T-1)(T-2) s^{T-3}(s-1)^{2}>0,
\end{aligned}
$$

for all $T>2$ and all $s>1$. We have thus established that (40) is strictly positive for values of $\beta$ between 0 and $\frac{r}{1+r T}$. We conclude that for any level of decay in that range, the ratio bounds of $\frac{2}{3}$ and $\frac{T}{T+1}$ hold. 


\section{References}

American Institute of Certified Public Accountants. (2007). Accounting Trends and Techniques, AICPA, New York, NY.

Arrow, K. (1964). "Optimal Capital Policy, Cost of Capital and Myopic Decision Rules," Annals of the Institute of Statistical Mathematics 1-2, 21-30.

Baker, M., Stein,J. and J. Wurgler. (2003). "When Does The Market Matter? Stock Prices and the Investment of Equity-Dependent Firms," Quarterly Journal of Economics, 118, 969-1005.

Basu, S. (1997). "The Conservatism Principle and the Asymmetric Timeliness of Earnings," Journal of Accounting and Economics 24, 3-37.

Beaver, W. and S. Ryan. (2000). "Biases and Lags in Book Value and their Effects on the Ability of the Book-to-Market Ratio to Predict Book Return on Equity," Journal of Accounting Research 38, 127-148.

Beaver, W. and S. Ryan. (2005). "Conditional and Unconditional Conservatism: Concepts and Modeling," Review of Accounting Studies 10, 260-309.

Belsey D., Kuh, E. and R. Welsch. (1980). Regression Diagnostics: Identifying Influential Data and Sources of Collinearity, John Wiley \& Sons, New York, NY.

Campbell, M. (2008). "The Drivers of the Levelized Cost of Electricity for Utility-Scale Photovoltaics," White Paper: Sunpower Corporation.

Dutta, S. and S. Reichelstein. (2005). "Accrual Accounting for Performance Evaluation," Review of Accounting Studies 10, 527-552.

Edwards, S. and S. Bell. (1961). The Theory and Measurement of Business Income, University of California Press, Berkeley, CA.

Ehrbar, A. (1998). The Real Key to Creating Wealth, John Wiley \& Sons, New York, NY.

Erickson, T. and T. M. Whited, (2000). "Measurement Error and the Relationship between Investment and q," Journal of Political Economy, 108, 1027-1057.

Fama, E. and K. French. (1992). "The Cross-section of Expected Stock Returns," Journal of Finance 47, 427-486.

Fama, E. and K. French. (1995). "Size and Book-to-Market Factors in Earnings and Returns," Journal of Finance 50, 131-155.

Fama, E. and K. French. (2006). "Profitability, Investments and Average Returns," Journal of Financial Economics 82, 491-518.

Fazzari, S., G. Hubbard, and B. Petersen. (1988). "Financing Constraints and Corporate Investment, Brookings Papers on Economic Activity, 1, 141-195. 
Fazzari, S., G Hubbard, and B. Petersen. (2000). "Investment-cash Flow Sensitivities Are Useful: A Comment on Kaplan-Zingales," Quarterly Journal of Economics, 115, 695705.

Feltham, G. and J. Ohlson. (1995). "Valuation and Clean Surplus Accounting for Operating and Financial Decisions," Contemporary Accounting Research 11, 689-731.

Feltham, G. and J. Ohlson. (1996). "Uncertainty Resolution and the Theory of Depreciation Measurement," Journal of Accounting Research 34, 209-234.

Gow, I., Ormazabal, G. and D. Taylor. (2010). "Correcting for Cross-Sectional and TimeSeries Dependence in Accounting Research," The Accounting Review 85, 483-512.

Hayashi, F. (1982). "Tobin's Marginal q and Average q: A Neoclassical Interpretation," Econometrica, 50, 213-224.

Healy, P., Myers, S. and C. Howe. (2002). "R\&D Accounting and the Tradeoff between Relevance and Objectivity." Journal of Accounting Research 40, 677-710.

Ibbotson and Associates. (2012). Stocks, Bonds, Bills and Inflation.

Iman, R. and W. Conover. (1979). "The Use of Rank Transform in Regression," Technometrics 21, 499-509.

Kaplan, S. and L. Zingales. (1997). "Do Investment Cash Flow Sensitivities Provide Useful Measures of Financing Constraints?" The Quarterly Journal of Economics, 112, 169215.

Landsman, W. and A. Shapiro. (1995). "Tobin's $q$ and the Relation Between Accounting ROI and Economic Return," Journal of Accounting, Auditing and Finance 10, 103-121.

Lakonishok, J., Shleifer, A. and R. Vishny (1994). "Contrarian Investment, Extrapolation and Risk," Journal of Finance 44, 1541-1578.

Lev, B. and T. Sougiannis. (1996). "The Capitalization, Amortization and Value-Relevance of R\&D," Journal of Accounting and Economics 21, 107-138.

Lindenberg, J. and S. Ross. (1981). "Tobin's $q$ and Industrial Organization," Journal of Business 54, 1-32.

Lewellen, W. and S.G. Badrinath. (1997). "On the Measurement of Tobin's q," Journal of Financial Economics 44, 77-122.

McNichols, M. and S. Stubben, (2008). "Does Earnings Management Affect Firms' Investment Decisions?" The Accounting Review, 83, 1571-1603.

Modigliani, F. and M. Miller, (1958). "The Cost of Capital, Corporation Finance and the Theory of Investment," The American Economic Review, 48, 261-297.

Mohanram, P. (2005). "Separating Winners from Losers Among Low Book-to-Market Stocks using Financial Statement Analysis," Review of Accounting Studies 10, 133-170. 
Nezlobin, A. (2012), "Accrual Accounting, Informational Sufficiency, and Equity Valuation," Journal of Accounting Research 50(1). 233-273.

Ohlson, J. and Z. Gao. (2006). "Earnings, Earnings Growth and Value," Foundations and Trends in Accounting.

Ohlson, J. (2009). "Risk, Growth and Permanent Earnings," Working Paper, Stern School of Business, New York University.

Penman, S. (1996). "The Articulation of Price-Earnings Ratios and Market-to-Book Ratios and the Evaluation of Growth," Journal of Accounting Research,34, 235-259.

Penman, S. and F. Reggiani. (2012). "Returns to Buying Earnings and Book Value: Accounting for Growth," Review of Accounting Studies forthcoming.

Penman, S., S. Richardson and I. Tuna. (2007). "The Book-to-Price Effect in Stock Returns: Accounting for Leverage," Journal of Accounting Research. 45,427-467.

Penman, S. and X. Zhang. (2002). "Accounting Conservatism, the Quality of Earnings and Stock Returns The Accounting Review 77. 237-264.

Peterson, M. (2009). "Estimating Standard Errors in Finance Panel Data Sets: Comparing Approaches," Review of Financial Studies 22, 435-480.

Piotroski, J. (2000). "Value Investing: The Use of Historical Financial Statement Information to Separate Winners from Losers," Journal of Accounting Research 38, 1-41.

Poterba, M., (1988). "Comment: Financing Constraints and Corporate Investment," Brookings Papers on Economic Activity 1, 200-206.

Rajan, M. and S. Reichelstein. (2009). "Depreciation Rules and the Relation between Marginal and Historical Cost," Journal of Accounting Research 47, 823-865.

Rajan, M., S. Reichelstein and M. Soliman. (2007). "Conservatism, Growth, and Return on Investment," Review of Accounting Studies 12, 325-370.

Rauh, J. (2006). "Investment and Financing Constraints: Evidence from the Funding of Corporate Pension Plans," The Journal of Finance 61, 33-71.

Reichelstein, S. (1997). "Investment Decisions and Managerial Performance Evaluation," Review of Accounting Studies 2, 157-180.

Rosenberg, K., Reid, K. and R. Lanstein. (1985). "Persuasive Evidence of Market Inefficiency," Journal of Portfolio Management 11, 9-17.

Roychowdhury, M. and R. Watts. (2007). "Asymmetric Timeliness of Earnings, Market-toBook and Conservatism in Financial Reporting," Journal of Accounting and Economics 44, 2-31.

Rogerson, W. (1997). "Inter-Temporal Cost Allocation and Managerial Investment Incentives: A Theory Explaining the Use of Economic Value Added as a Performance Measure," Journal of Political Economy 105, 770-795. 
Rogerson, W. (2008). "Intertemporal Cost Allocation and Investment Decisions," Journal of Political Economy 116, 931-950.

Rogerson, W. (2011). "On the Relationship Between Historic Cost, Forward Looking Cost and Long Run Marginal Cost," Review of Network Economics10(2). Article 2.

Roll, R. and J. Weston. (2008). "Average and Marginal Tobins $q$ as Indicators of Future Growth Opportunities, Expected Return, and Risk," Working Paper, UCLA.

Ross, S., Westerfield, R., and J. Jaffe. (2005). Corporate Finance, McGraw-Hill Press, New York, NY.

Ryan, S. (1995). "A Model of Accrual measurement with Implications for the Evaluation of the Book-to-Market Ratio," Journal of Accounting Research 33, 95-112.

Staehle, M. and N. Lampenius. (2010). "Are PE- and MB-Ratios Susceptible to Accruals, Growth and Profitability?," Working paper, University of Hohenheim, Germany.

Tobin, J. (1969). "A General Equilibrium Approach to Monetary Theory," Journal of Money, Credit and Banking, 1, 15-29.

Vuong, Q. H. (1989). "Likelihood Ratio Tests for Model Selection and Non-nested Hypotheses," Econometrica, 57, 307-333.

Watts, R. (2003). "Conservatism in Accounting Part I: Explanations and Implications," Accounting Horizons 17, 207-221.

Zhang, X. (1998). "The Analysis of Line Items in Earnings Forecasting and Equity Valuation," Ph.D. Dissertation, Graduate School of Business Columbia University.

Zhang, X. (2000). "Conservative Accounting and Equity Valuation," Journal of Accounting and Economics 29, 125-149. 